Article

\title{
A Comparison of Wind Flow Models for Wind Resource Assessment in Wind Energy Applications
}

\section{Nicolas Gasset ${ }^{1}$, Mathieu Landry ${ }^{2}$ and Yves Gagnon ${ }^{2, *}$}

1 École de Technologie Supérieure, 1100 Notre-Dame Ouest, Montréal, QC H3C 1K3, Canada; E-Mail: nicolas.gasset@gmail.com

2 K.C. Irving Chair in Sustainable Development, Université de Moncton, Moncton, NB E1A 3E9, Canada; E-Mail: mathieu.landry@umoncton.ca

* Author to whom correspondence should be addressed; E-Mail: yves.gagnon@umoncton.ca; Tel.: +1-506-858-4152; Fax: +1-506-863-2110.

Received: 10 August 2012; in revised form: 22 October 2012 / Accepted: 23 October 2012 / Published: 29 October 2012

\begin{abstract}
The objective of this work was to assess the accuracy of various coupled mesoscale-microscale wind flow modeling methodologies for wind energy applications. This is achieved by examining and comparing mean wind speeds from several wind flow modeling methodologies with observational measurements from several $50 \mathrm{~m}$ met towers distributed across the study area. At the mesoscale level, with a $5 \mathrm{~km}$ resolution, two scenarios are examined based on the Mesoscale Compressible Community Model (MC2) model: the Canadian Wind Energy Atlas (CWEA) scenario, which is based on standard input data, and the CWEA High Definition (CWEAHD) scenario where high resolution land cover input data is used. A downscaling of the obtained mesoscale wind climate to the microscale level is then performed, where two linear microscale models, i.e., MsMicro and the Wind Atlas Analysis and Application Program (WAsP), are evaluated following three downscaling scenarios: CWEA-WAsP, CWEA-MsMicro and CWEAHD-MsMicro. Results show that, for the territory studied, with a modeling approach based on the MC2 and MsMicro models, also known as Wind Energy Simulation Toolkit (WEST), the use of high resolution land cover and topography data at the mesoscale level helps reduce modeling errors for both the mesoscale and microscale models, albeit only marginally. At the microscale level, results show that the MC2-WAsP modeling approach gave substantially better results than both MC2 and MsMicro modeling approaches due to tweaked meso-micro coupling.
\end{abstract}


Keywords: wind flow models; wind resource assessment; WAsP; MC2; MsMicro; microscale; mesoscale

\section{Introduction}

The creation of a wind atlas to map the geographical distribution of the wind resource potential over a territory is often the first step for the sustainable development of a wind energy sector [1]. It can be used to identify the best sites for more advanced studies and to optimize economical and territorial planning.

In Canada, the Canadian Meteorological Centre (CMC) of Environment Canada (EC) has historically had extensive experience in the development of wind flow models. Building from early experiences such as the Askervein Hill project [2] and wind energy resource maps [3], EC contributed a series of models and tools [4,5] that recently converged to the Wind Energy Simulation Toolkit (WEST): a methodology to achieve numerical wind atlas and resource maps ranging from the regional scale (mesoscale) to the local scale (microscale). Such a combined mesoscale-microscale modelling appears to be the best suited to assess the wind resource over a territory as underlined by Landberg et al. [6]. The WEST method is based on a statistical-dynamical downscaling approach borrowed to the climatology domain [7] that integrates the Compressible Community Mesoscale Model (MC2) [8] and the MsMicro microscale model [9]. In 2005, MC2 was applied, through an early version of the WEST, to obtain the Canadian Wind Energy Atlas (CWEA) at $5 \mathrm{~km}$ horizontal resolution [4] (i.e., application of the WEST only at the mesoscale level). Each mesh of the CWEA includes the mean velocity and power density of the surface winds, along with the local wind climates allowing for more advanced wind resource studies, as well as the computation of a wind turbine's electricity production. However, a $5 \mathrm{~km}$ resolution is still too coarse for a realistic and detailed local (microscale) description and quantification of the wind resource.

To this end, and since the WEST model was not publicly accessible at that time, a similar approach was developed where the CWEA is used as input meteorological data and, integrating information on topography and land use, the Wind Atlas Analysis and Application Program (WAsP) microscale model [10] is used to obtain high resolution $(200 \mathrm{~m})$ wind climate and resource maps. This method was initially applied to generate the wind atlas of the province of Prince Edward Island (PEI), Canada [11].

Since the development of the PEI Wind Atlas, the full WEST method has been integrated in the Canadian Hydraulic Centre's EnSim proprietary Windows-based geographical information system to create Anemoscope [12], and an Open Source Edition (OSE) of the WEST has also been released [13]. Both of these end-user applications provide in addition of the models, the large scale wind climate data (statistics) and surface data (topography and land use) covering the whole world.

Subsequently, the WEST approach was applied to develop the high resolution (200 $\mathrm{m})$ wind atlases for the neighbouring Canadian provinces of New Brunswick and Nova Scotia $[14,15]$. However, to date, a direct comparison of the results from these different wind flow modeling methodologies has not been made, which is the objective of the present work. 
In this study, mean wind speed values from several wind flow modeling methodologies are evaluated. At the mesoscale level, with a $5 \mathrm{~km}$ horizontal resolution, two scenarios are examined based on the MC2 model. Both scenarios use the same large scale input wind climate data but one uses the Anemoscope's provided land cover description, and it is named here CWEA, while the second scenario, named CWEAHD, is based on an up-to-date high resolution land cover description provided by the province of PEI. In addition, at the microscale level, with a $200 \mathrm{~m}$ horizontal resolution, comparisons are done between three scenarios: a MC2-WAsP modeling approach, where the WAsP microscale model is coupled to the MC2 mesoscale model, and two other scenarios based on a MC2-MsMicro modeling approach (WEST standard approach), where the MsMicro microscale model is coupled to the MC2 mesoscale model. In both the mesoscale and microscale analyses, modeling results are compared to observational mean wind speed measurements from several $50 \mathrm{~m}$ met towers distributed across the study area.

\section{Method}

\subsection{Study Area: Prince Edward Island}

Prince Edward Island (PEI, Figure 1), is the smallest of the Canadian provinces, both in size $\left(900 \mathrm{~km}^{2}\right)$ and in population (141,551 residents). Located in the Gulf of Saint Lawrence, and part of the Maritime Provinces on the eastern coast of Canada, the island has few natural resources and the major part of the electricity consumed on the province of PEI is produced on the continent in the provinces of New Brunswick and Nova Scotia. However, due to its location and the geophysical features surrounding the island (border between a continental and a maritime climate, the Gulf of Saint Lawrence, the cold Current of Labrador and the Gulf Stream), it is known to have a good wind resource potential. As a result, the province of PEI has started to develop wind farms as a means to satisfy its own electricity demand and eventually export electricity. With an installed capacity of $166 \mathrm{MW}$, the total wind penetration in the province is currently approximately $21 \%$ [16]. Furthermore, the province has recently announced plans to develop an extra $500 \mathrm{MW}$ of wind energy projects on the island, both for the internal and export markets [17]. Because of the high penetration rate, the precise sitting of future wind farms based on modeling tools, such as those used in this study, will be one of the key challenges in order to achieve this ambitious goal.

In its strategy for the exploitation of its wind resource for energy generation, the province of PEI has established a comprehensive wind measurement program, thus providing accurate, long term wind measurements throughout the territory. This dataset renders the province of PEI as an ideal site to evaluate wind resource modeling methodologies, which is the objective of this study. 
Figure 1. World location and main characteristics of the province of Prince Edward Island (PEI), Canada.

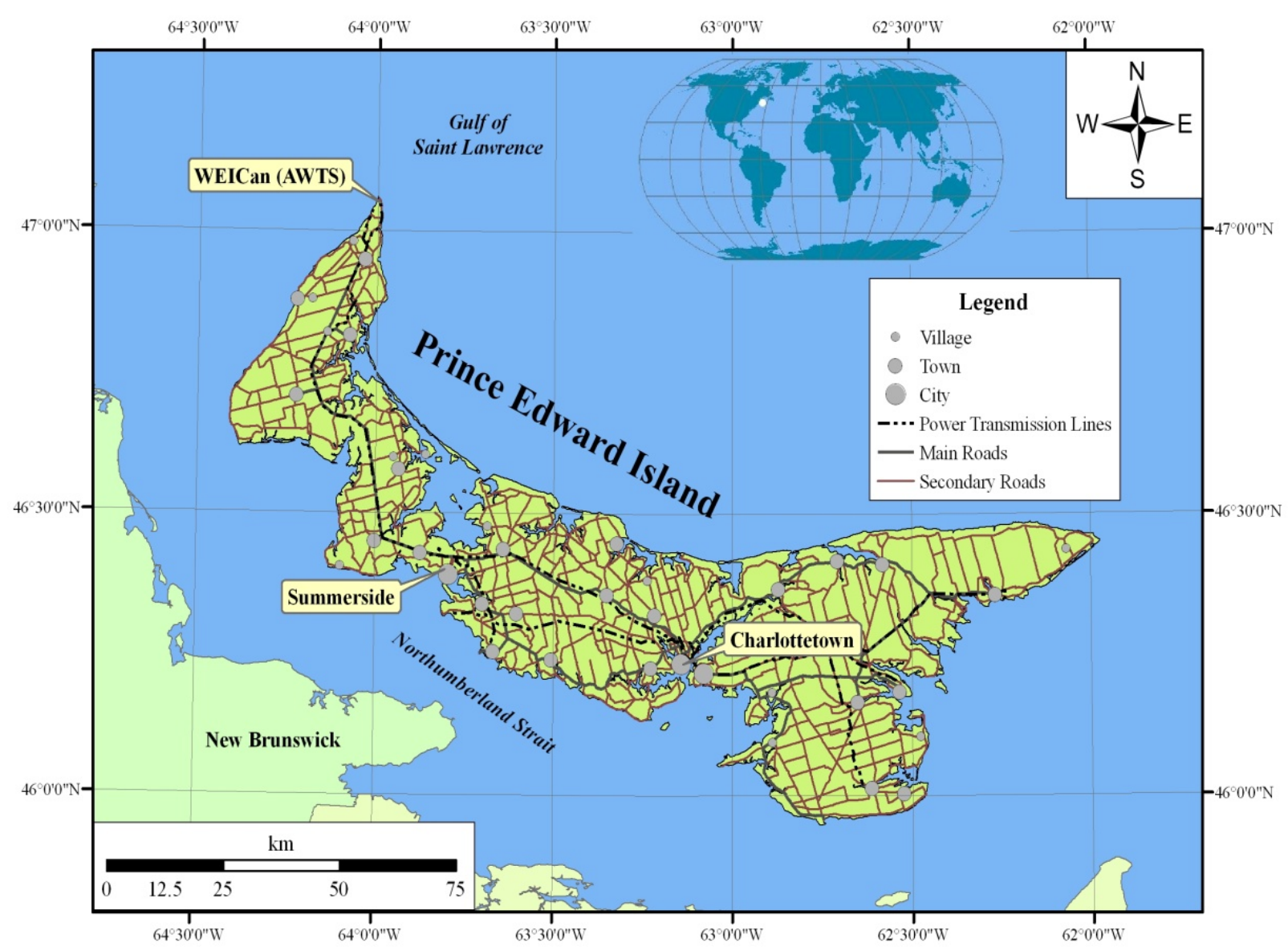

\subsection{Models}

Several methods are available to model the wind in the atmospheric boundary layer (ABL) at both the mesoscale and the microscale levels [6,18,19]. Depending on the application and the information needed, assumptions can be made that greatly simplify the problem at the price of representativeness [20,21]. In a general sense, the temporal, horizontal and vertical scales of the problem, as well as more practical considerations characterize the choice of ABL modelling approach. In the present study, the best suited approach to achieve wind resource assessment over a territory of the size of the province of PEI appears to be the combined mesoscale-microscale modelling [5,6,22,23].

Mesoscale models are primarily aimed to reproduce large scale unsteady environmental flows. Thus, in addition to wind velocity and pressure, temperature and humidity are important variables, while the temporal evolution of the flow as well as the earth rotation and geometry are critical aspects in those models. Mesoscale phenomenon sizes range from a couple of thousand to a couple of kilometres [20,21]; however, the finest mesoscale processes induced by topography and surface discontinuities (i.e., below $10 \mathrm{~km}$ ) are the most challenging to reproduce. The latter requires the model to be at least non-hydrostatic and at best fully elastic [20,24].

In the context of wind resource estimation, mesoscale models are able to take into account the influence of large scale geophysical features on the atmospheric flow and thus on the wind resource. 
However, accuracy is required and the fine mesoscale processes are of importance $[8,22,23]$. In addition, a sufficiently advanced model of the ABL is required to properly take into account both the energy exchanges with the earth surface and the turbulent mixing influenced by thermal stratification. A one-and-a half order turbulence closure (i.e., in which a transport equation for the turbulent kinetic energy (TKE) is solved and eddy viscosity is proportional to the product of the square root of the TKE and a mixing length) or higher is required to reproduce a full diurnal cycle [21].

For its part, MC2 is an operational like research mesoscale model. It solves the fully compressible Euler equation of motion based on an efficient Semi-Implicit Semi-Lagrangian time stepping approach $[5,8,24]$. The dynamic kernel of MC2 is thus skillful to reproduce the wide range of flow structures present in the atmosphere [24]. As a comparison, it is more advanced than two other commonly used mesoscale models for wind resource estimation, i.e., the Karlsruhe Atmospheric Mesoscale Model (KAMM) [22] and the Mesoscale Atmospheric Simulation System (MASS), an evolution of the Mesoscale Model 5 (MM5) [25], which were proven to give very satisfying results. Concerning the processes that are modelled (including the ABL model), MC2 share its library with the operational model used for the everyday weather forecast at EC; it thus includes the most advance features available. The ABL is taken into account thanks to a column model fully aware of thermal stratification and which is based on a one-and-a-half order turbulence closure [8]. The ABL model is thus very similar to what is implemented in KAMM and MASS [22,25]. MC2 was proven to perform well in the finest mesoscales and more generally, to be as skilled as the most advanced mesoscale models [8,24]. Furthermore it has been applied successfully for large scale wind resource assessments $[4,5,8,14,15,24]$.

Microscale models, on the other hand, are dedicated to atmospheric processes that do not exceed a couple of kilometres (i.e., scales for which the earth's rotation no longer has an impact) [20,21]. In the context of wind resource estimation, they are dedicated to the modelling of the flow in the lowest part of the ABL, i.e., the surface layer. Generally, in these applications, the flow is commonly considered as neutral $[5,18,19,22,26]$. Methods to predict wind fields in the surface layer range from the simplest model, strongly relying on flow assumptions (such as a mass-conserving model or the slightly more evolved linearize Navier Stokes equation model), to advanced and more universal Computational Fluid Dynamics (CFD) models such as the Reynolds Averaged Navier Stokes (RANS) and Large Eddy Simulation (LES) models [6,18,19]. However, while an increase in the complexity of the model generally results in an increase of the computational cost, it does not necessary imply that better results are obtained $[6,18,19,26]$. Indeed, linear models, such as the ones based on the Jackson and Hunt model [27] of flow over low hills, i.e., WAsP [10] and MsMicro [9], require a fraction of the computational cost of the RANS methods and are proven to be as capable to reproduce the average neutral ABL velocity fields over gentle terrains, i.e., when the slope of the surface is lower than 0.3 (values at which separation of the flow becomes highly probable) $[6,9,18,19,28]$. WAsP and MsMicro differ in their approach to include surface roughness and roughness changes, where the method used by WAsP appears to be slightly more evolved $[9,18,29]$. Furthermore, in comparison to microscale models based on mass conservation only, such as MINERVE [28] or WindMap [30], linear models are less dependent of the input data location and density [28]. At the opposite end, more advanced CFD approaches are generally used when the site topography is more complex, when a more detailed picture of the turbulence over a site is needed, or in order to better take into account the thermal 
stratification in the ABL $[6,18,19,26]$. However, CFD approaches are more tricky to apply than linear models $[19,26]$ and the computational cost of the former is increased by at least a hundred fold. Those facts explain the current high level of interest for linear models in the wind industry $[6,18,19]$.

In the present study, it is to underline that, as it can be seen on Figure 2, the topography of the province of PEI is relatively smooth and slopes higher than 0.3 are only observed in very few spots on the island. Thus, linear models such as WAsP and MsMicro, appear to be well suited for the microscale wind resource evaluation of this study area.

Figure 2. High resolution topography of the province of Prince Edward Island (PEI), Canada.

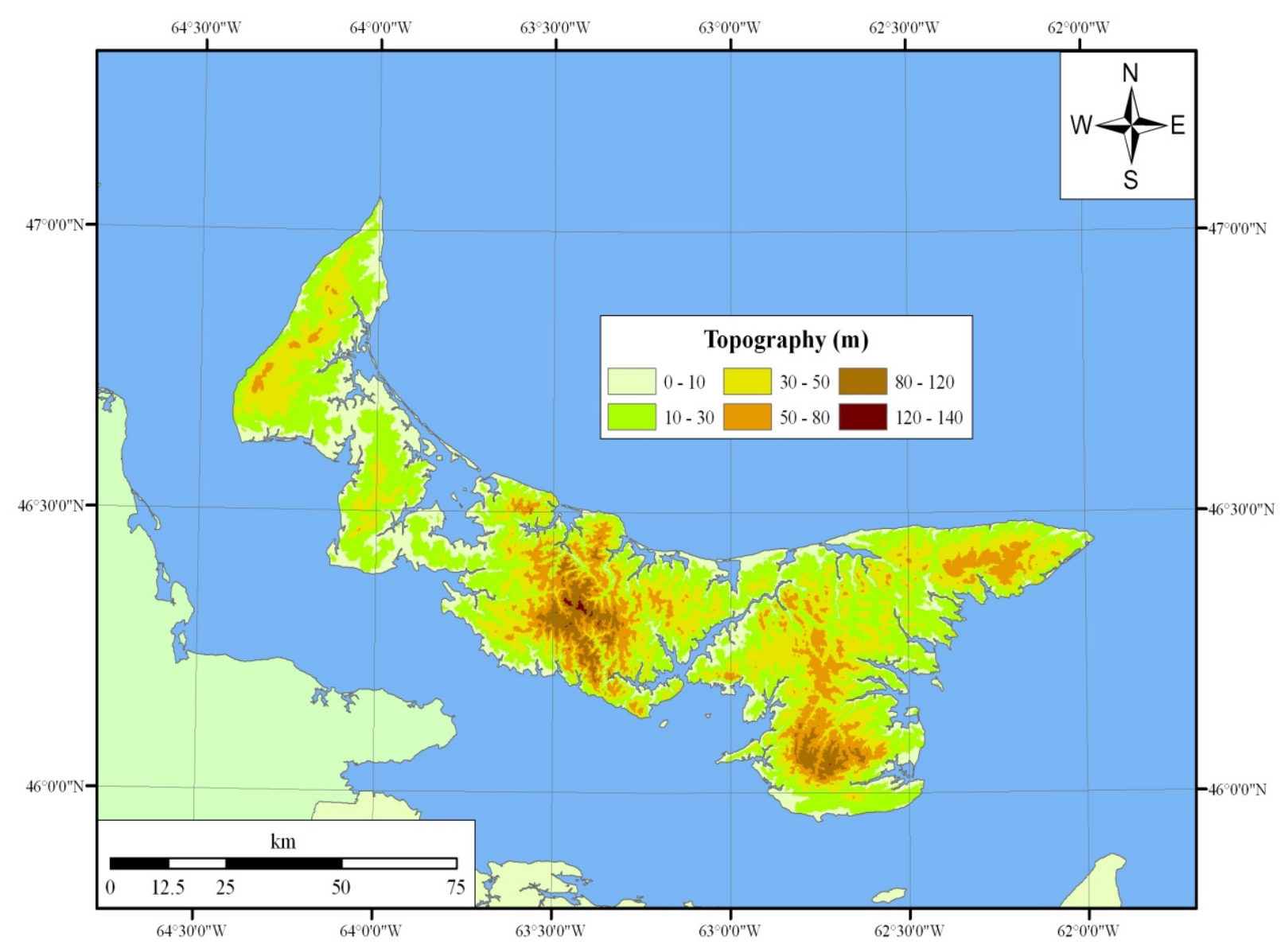

Finally, concerning the mesoscale-microscale coupling, the WEST method integrates MC2 and MsMicro, while an alternative approach introduced in this study couples the CWEA dataset, i.e., results from MC2, with WAsP. Both of these approaches are very similar to the KAMM-WAsP method [22] developed at the Risø National Laboratory, Denmark, and which has been proven to lead to very satisfying results [6,22]. The statistical-dynamical downscaling philosophy is identical [5,22]: the large scale geostrophic wind (from a rawinsonde or from analysis of reanalysis database) is classified by velocity class and wind rose sector (temperature profile and wind shear can also be taken into account) to obtain the large scale wind climate (representative for the surrounding couple of hundred kilometres $[6,7,20]$ ), then each class of this wind climate is modelled with a mesoscale model (relying on the hydrostatic and geostrophic basic state to initialize the model) and results are 
recombined based on the frequency of each wind climate class in order to obtain the mesoscale wind climate $[5,7,22]$. Finally, a similar approach is followed to go from the mesoscale to the microscale level, albeit microscale models are used [5,22]. This statistical-dynamical downscaling approach differs slightly from the combine mesoscale-microscale MesoMap system [30] developed by AWS Truepower which is also proven to lead to satisfying results [23]. The latter is based on the modeling with the mesoscale model MASS of 366 representative days selected in a reanalysis database. These results are then combined to obtain the mesoscale wind climate dataset. Finally, based on this dataset, a mass-conserving wind flow model, WindMap, is used to compute the microscale wind climate [30].

Both WEST/KAMM-WAsP and MesoMap statistical-dynamical downscaling philosophies are proven to be as capable [22,23]; however, the latter may appear more efficient as less cases might need to be modelled with the mesoscale model while allowing to explicitly account of local phenomena such as sea breeze $[5,7,22]$. As a consequence of the above, results of an equivalent quality as with the KAMM-WAsP method and the MesoMap methods are thus expected in the present study by using the full WEST method (which is an end-user application publicly available as opposed to the two former) and the alternative coupling approach of MC2-WAsP.

\subsection{Scenarios}

In this study, at the mesoscale level, two wind flow modeling approaches based on MC2are used to develop mesoscale maps at $50 \mathrm{~m}$ above ground level (agl) with a $5 \mathrm{~km}$ horizontal resolution for the entire province of PEI:

- CWEA mesoscale scenario: In this scenario, large scale wind climate data based on the NCEP/NCAR global Reanalysis data [31] is used as input data of the MC2 model together with the US Geological Survey (USGS) global topography and global land cover datasets (approximately $1 \mathrm{~km}$ resolution) [32].

- CWEAHD mesoscale scenario: In this scenario, the same resolution and large scale wind climate input data are used as input data of the MC2 model but the surface description is based on up-to-date high resolution (30 $\mathrm{m}$ resolution) topography and land cover data.

For all scenarios, the MC2 mesoscale model is set up with a horizontal grid of $100 \times 100$ grid points having a spacing of $5 \mathrm{~km}$ centered on the province of PEI. In the vertical, the first mesh is at $50 \mathrm{~m}$ above ground level (agl) while the top boundary is at $10,000 \mathrm{~m}$ above sea level. A total of 25 meshes are used with 15 grid points in the lowest $1500 \mathrm{~m}$. The time step is $40 \mathrm{~s}$ and the model is run for 810 times steps regardless of the wind climate class reproduced. The output wind climate data from MC2 (i.e., the input of the microscale model) is calculated based on the $50 \mathrm{~m}$ agl grid level. This set-up follows the guide-lines of the WEST model, and in fact, it is very similar to what was used to compute the Canadian Wind Energy Atlas [4]. The model could be further optimized notably by reducing the grid size, but it is not the primary objective of the current study. Furthermore, results obtained with the above setup are identical to the Canadian Wind Energy Atlas dataset for the CWEA scenario, thus confirming the proper use of the WEST mesoscale module. As seen later, this allows the comparison of the PEI wind atlas results [11] with the WEST microscale results. 
Concerning the downscaling at the microscale level, both WAsP and MsMicro models are used in order to develop microscale wind resource maps at $50 \mathrm{~m}$ agl with a $200 \mathrm{~m}$ horizontal resolution for the entire province of PEI. From these models, three microscale scenarios are evaluated:

- CWEA-WAsP microscale scenario: In this scenario, the CWEA data, at $5 \mathrm{~km}$ resolution, is used as the regional wind climate input data of the WAsP microscale model.

- CWEA-MsMicro microscale scenario: In this scenario, the CWEA data, at $5 \mathrm{~km}$ resolution, is used as the regional wind climate input data of the MsMicro microscale model.

- CWEAHD-MsMicro microscale scenario: In this scenario, the CWEAHD mesoscale data, at $5 \mathrm{~km}$ resolution, is used as the regional wind climate input data of the MsMicro microscale model.

Table 1 summarizes the scenarios while further details on the input data used in each scenario are given in the next section.

Table 1. Summary of the wind flow modeling approaches used in the study.

\begin{tabular}{|c|c|c|c|c|c|}
\hline & $\begin{array}{l}\text { Wind } \\
\text { data }\end{array}$ & $\begin{array}{c}\text { Topography } \\
\text { data }\end{array}$ & $\begin{array}{c}\text { Landcover } \\
\text { data }\end{array}$ & $\begin{array}{c}\text { Mesoscale } \\
\text { model }\end{array}$ & $\begin{array}{c}\text { Microscale } \\
\text { model }\end{array}$ \\
\hline \multicolumn{6}{|l|}{ Mesoscale scenarios } \\
\hline CWEA & $\begin{array}{c}\text { NCEP/NCAR } \\
\text { reanalysis }\end{array}$ & $\begin{array}{c}\text { USGS } \\
\text { (1 km resolution) }\end{array}$ & $\begin{array}{c}\text { USGS } \\
(1 \mathrm{~km} \text { resolution })\end{array}$ & $\mathrm{MC} 2$ & - \\
\hline CWEAHD & $\begin{array}{c}\text { NCEP/NCAR } \\
\text { reanalysis }\end{array}$ & $\begin{array}{c}\text { Canadian Digital } \\
\text { Elevation Data (CDED) } \\
(30 \text { m resolution })\end{array}$ & $\begin{array}{c}\text { PEI Corporate Land } \\
\text { Use Inventory } \\
\text { (30 m resolution) }\end{array}$ & $\mathrm{MC} 2$ & - \\
\hline \multicolumn{6}{|l|}{ Microscale scenarios } \\
\hline CWEA-MsMicro & $\begin{array}{l}\text { CWEA mesoscale } \\
\text { scenario }\end{array}$ & $\begin{array}{c}\text { Canadian Digital } \\
\text { Elevation Data (CDED) } \\
(30 \mathrm{~m} \text { resolution })\end{array}$ & $\begin{array}{c}\text { PEI Corporate Land } \\
\text { Use Inventory } \\
\text { (30 m resolution) } \\
\text { MsMicro classification }\end{array}$ & MC2 & MsMicro \\
\hline CWEAHD-MsMicro & $\begin{array}{c}\text { CWEAHD mesoscale } \\
\text { scenario }\end{array}$ & $\begin{array}{c}\text { Canadian Digital } \\
\text { Elevation Data (CDED) } \\
(30 \mathrm{~m} \text { resolution })\end{array}$ & $\begin{array}{c}\text { PEI Corporate Land } \\
\text { Use Inventory } \\
\text { (30 m resolution) } \\
\text { MsMicro classification }\end{array}$ & MC2 & MsMicro \\
\hline CWEA-WAsP & $\begin{array}{c}\text { CWEA mesoscale } \\
\text { scenario }\end{array}$ & $\begin{array}{c}\text { Canadian Digital } \\
\text { Elevation Data (CDED) } \\
(30 \text { m resolution })\end{array}$ & $\begin{array}{l}\text { PEI Corporate Land } \\
\text { Use Inventory } \\
\text { (30 m resolution) } \\
\text { WAsP classification }\end{array}$ & MC2 & WAsP \\
\hline
\end{tabular}

In regards to the coupling of the mesoscale-microscale models, for the CWEA-MsMicro and CWEAHD-MsMicro scenarios, the WEST integrated approach implemented in Anemoscope is used. The output from the MsMicro microscale model is the wind climate data at $50 \mathrm{~m}$ agl on a $500 \times 500$ mesh with $200 \mathrm{~m}$ horizontal resolution. The reader is referred to the study of $\mathrm{Yu}$ et al. [5] for further details of the MC2-MsMicro coupling. 
For the CWEA-WAsP scenario, no such convenient coupling approach exists, and the use of the CWEA dataset as input of the WAsP microscale model required additional manipulations. WAsP is designed to use, as its input wind climate data, either an "observed wind climate" dataset (punctual wind properties at a given height and influenced by surrounding terrain and landscape) or a "regional wind climate" dataset (also called wind atlas in WAsP which represents the wind properties at several height and for several roughness above a flat terrain). Along with the "observed wind climate" dataset, a description of the roughness and topography are required to produce a "regional wind climate" which is then used by WAsP for wind resource mapping and wind farm design [10,29]. In this study, it is decided to consider the CWEA data as a multitude of "observed wind climate" dataset and to provide WAsP with mesoscale surface property descriptions, i.e., roughness and topography maps. This allows WAsP to transform, or deinfluence, the CWEA wind climate data in order to obtain a "regional wind climate" dataset on which all resource computations are based. Concerning the computational procedure, since the WAsP microscale model can only take into account one "observed wind climate" dataset per computation, each CWEA mesh requires its own computational domain. As a result, based on the input data presented above, as many domains are generated as there are grid points of the CWEA output wind climate dataset within the study area. To this end, 454 computational wind resource grids of $10 \mathrm{~km}$ by $10 \mathrm{~km}$ having a horizontal resolution of $200 \mathrm{~m}$ are used to cover the entire province of PEI. Finally, a weighting function is used to merge the wind resource grids such as the merge result, $\Psi_{i j}$, of any variable, $\psi_{i_{k} j_{k}}^{k}$, from the resource grid, $k$, is obtained by:

$$
\Psi_{i j}=\frac{\sum_{k} \psi_{i_{k} j_{k}}^{k} l_{p_{i_{k}} j_{k}}^{k}}{\sum_{k} l_{p_{i_{k}} j_{k}}^{k}}
$$

where the weighting function is given by:

$$
l_{p_{i_{k} j_{k}}}^{k}=\left(l_{\text {max }}^{k}-l_{c_{i_{k} j_{k}}}^{k}\right)^{2}
$$

where $l_{\text {max }}^{k}$ equals the mid-diagonal length of the resource grid, $k, l_{c_{i_{k} j_{k}}}^{k}$ the distance of the mesh, $i_{k}, j_{k}$ to the centre of the resource grid, $k$, and where the local indices, $i_{k}$ and $j_{k}$ of the domain, $k$, are directly corresponding to the global indices, $i$ and $j$. In this study, the output wind climate data was calculated at $50 \mathrm{~m}$ agl for all microscale scenarios.

\subsection{Input Data}

To model the wind resource potential using most mesoscale and microscale methods, two main types of data are needed: surface data and wind climate data [18]. Surface data describes the surface properties needed for the wind resource estimation [6], namely the topography and the surface roughness height. In this section, the specific characteristics of the surface and wind climate data are presented. 
For both CWEA and CWEAHD mesoscale scenarios, the provided large scale wind climate based on the NCEP/NCAR Reanalysis dataset [31], which covers a period of 43 years (1953-2000) with a sampling of 6 hours, is used for the wind climate data. The NCEP/NCAR Reanalysis dataset has a horizontal resolution of 2.5 degrees (global coverage) and a vertical resolution of 28 sigma levels. In the CWEA mesoscale scenario, the topography and land cover datasets are taken from the US Geological Survey (USGS) database at a scale of 1:250,000 (resolution of approximately $1 \mathrm{~km}$ ), while in the CWEAHD mesoscale scenario and in the subsequent microscale scenarios, both of these datasets are replaced with high resolution topography and land cover datasets: the Canadian Digital Elevation Data (CDED) [33] at a scale of 1:50,000 (resolution of approximately $30 \mathrm{~m}$ ) is used for the high resolution topography database while the PEI Corporate Land Use Inventory [34] is used for the high resolution land cover database.

Figure 2 shows the CDED high resolution topography of PEI. As it can be seen from Figure 2, the topography of PEI consists of gently rolling hills of which the area which cuts through the central part of the province contains its highest point at approximately $135 \mathrm{~m}$ above sea level.

For its part, the PEI Corporate Land Use Inventory consists of vector digital data (polygon shape files) at a scale of 1:17,000 (details of $1.5 \mathrm{~m}$ ), and based on an extensive land cover description (76 classes). It stands for what is on the ground (e.g., low height crops, balm forest, marsh, etc.), and each polygon is represented by the percentage of the seven most present classes of land cover.

Anemoscope conveniently provides the full set of tools to transform the high resolution land cover descriptions to a roughness height grid at the mesoscale and microscale model resolutions. This allows to directly integrate the PEI Corporate Land Use Inventory [34] into Anemoscope in order to produce input roughness data for the CWEAHD, CWEA-MsMicro and CWEAHD-MsMicro scenarios. Table 2 presents the resulting roughness values associated with the 76 cover classes of the PEI Corporate Land Use Inventory. As a side note, it is to underline that not using the same land cover dataset at the mesoscale and microscale level, as it is the case for the CWEA-MsMicro scenario may introduce inconsistencies.

A separate approach was however needed for the CWEA-WAsP microscale scenario as WAsP and MC2-MsMicro were found to have incompatible roughness descriptions: WAsP requires roughness values below $1 \mathrm{~m}$ while the roughness obtained from Anemoscope (and from the Canadian Wind Energy Atlas) can be notably higher. Indeed, as discussed by Wieringa [35] several roughness classifications exists and the values associated with a particular land cover class can differ depending on the specificities and restrictions of the approach. Furthermore, the method to aggregate the roughness of various surface cover into a coarser representation may have a notable impact on the final roughness map. As a result, and in consideration of the above, it was decided to create WAsP specific mesoscale and microscale roughness datasets based on the PEI Land Use Inventory dataset. To this end, based on Wieringa considerations [35], the 76 cover classes of the PEI Corporate Land Use Inventory are first converted to roughness values following Table 2 . This dataset is then averaged to the desired resolution mesh based on logarithmic means:

$$
\ln \left(z_{0_{\text {out }}}(k, l)\right)=\frac{\sum_{i} \sum_{j} \ln \left(z_{0_{\text {in }}}(i, j)\right) A(i, j)}{\sum_{i} \sum_{j} A(i, j)}
$$


where $z_{0_{\text {out }}}(k, l)$ is the output roughness length $(\mathrm{m})$ at the output grid node $k, l ; z_{0_{\text {in }}}(i, j)$ is the input roughness length (m) at the input grid node $i, j$ and $A(i, j)$ is the area $\left(\mathrm{m}^{2}\right)$ of the input grid mesh $i, j$. Following this approach, the extensive land cover description of PEI can be smoothened and more control is acquired on the microscale model inputs. As a side note, some of the classes in Table 2 present a roughness height higher than the WAsP limit of $1 \mathrm{~m}$. In fact, these represent the roughness values before averaging with the above method. It was decided to use values higher than the WASP limit of $1 \mathrm{~m}$ for a few classes in order for the meshes that contain such elements to have a higher and more representative roughness value after applying the above averaging method, after which all roughness values in the dataset were lower than the WASP limit.

Table 2. Identification between landcover and roughness height.

\begin{tabular}{|c|c|c|c|}
\hline \multirow[b]{2}{*}{ Code } & \multirow[b]{2}{*}{ Land cover class } & \multicolumn{2}{|c|}{ Roughness height z0 (m) } \\
\hline & & MC2 \& MsMicro & WAsP \\
\hline \multicolumn{4}{|c|}{ Agriculture } \\
\hline \multicolumn{2}{|c|}{ All agricultural classes are given the same roughness height } & 0.08 & 0.05 \\
\hline \multicolumn{4}{|l|}{ Forest } \\
\hline \multicolumn{2}{|c|}{ Most forest classes are given the same roughness height } & 1.5 & 0.8 \\
\hline $\mathrm{CC}$ & Clear cut & 0.08 & 0.05 \\
\hline DT & Dead tree & 0.8 & 0.5 \\
\hline $\mathrm{IH}$ & Intolerant hardwood & 0.8 & 0.5 \\
\hline \multicolumn{4}{|l|}{ Wet } \\
\hline BOW & Bog & 0.05 & 0.05 \\
\hline BKW & Brackish marsh & 0.05 & 0.05 \\
\hline DMW & Deep marsh & 0.01 & 0.01 \\
\hline MDW & Meadow & 0.05 & 0.05 \\
\hline OWW & Open water & 0.001 & 0.001 \\
\hline SAW & Salt marsh & 0.05 & 0.05 \\
\hline SDW & Sand dune & 0.05 & 0.05 \\
\hline SFW & Seasonally flooded flat & 0.1 & 0.1 \\
\hline SMW & Shallow marsh & 0.05 & 0.05 \\
\hline SSW & Shrub swamp & 0.15 & 0.3 \\
\hline WSW & Wooded swamp & 1.0 & 0.5 \\
\hline \multicolumn{4}{|c|}{ Non Forest, Non Agriculture, Non Wet } \\
\hline BAR & Bare soil & 0.05 & 0.05 \\
\hline BSB & Nackshore beach & 0.05 & 0.05 \\
\hline BLD & Building & 1.35 & 2 \\
\hline WWW & Coastal inlet water & 0.001 & 0.001 \\
\hline GRS & Grass & 0.08 & 0.2 \\
\hline PAV & Paved & 0.01 & 0.01 \\
\hline SHR & Shrubs & 0.15 & 0.7 \\
\hline TRE & Trees & 1.5 & 1.1 \\
\hline WAT & Water (fresh) & 0.001 & 0.01 \\
\hline
\end{tabular}


The roughness heights map for both mesoscale CWEA and CWEAHD scenarios are shown in Figures 3 and 4, respectively. By comparing Figures 3 and 4, it can be seen that the roughness height values are less uniform across the province in the CWEAHD scenario, which reflect the higher resolution land cover dataset. Figure 5 shows the roughness height bias between the CWEAHD and CWEA scenarios. The mesoscale roughness height bias shows that the CWEAHD scenario has a higher roughness height in the central to western areas of the province, while the eastern area of the province features slightly smaller roughness values in CWEAHD scenario. The differences between CWEA and CWEAHD roughness maps can entirely be attributed to the up-to-date PEI Land Cover Inventory dataset. Furthermore, seeing those differences, it is to underline that the consistency between mesoscale and microscale roughness description is higher in the CWEAHD-MsMicro scenario than for the CWEA-MsMicro where different input datasets are used at both the mesoscale and microscale level.

Figure 3. Mesoscale roughness height for CWEA scenario.

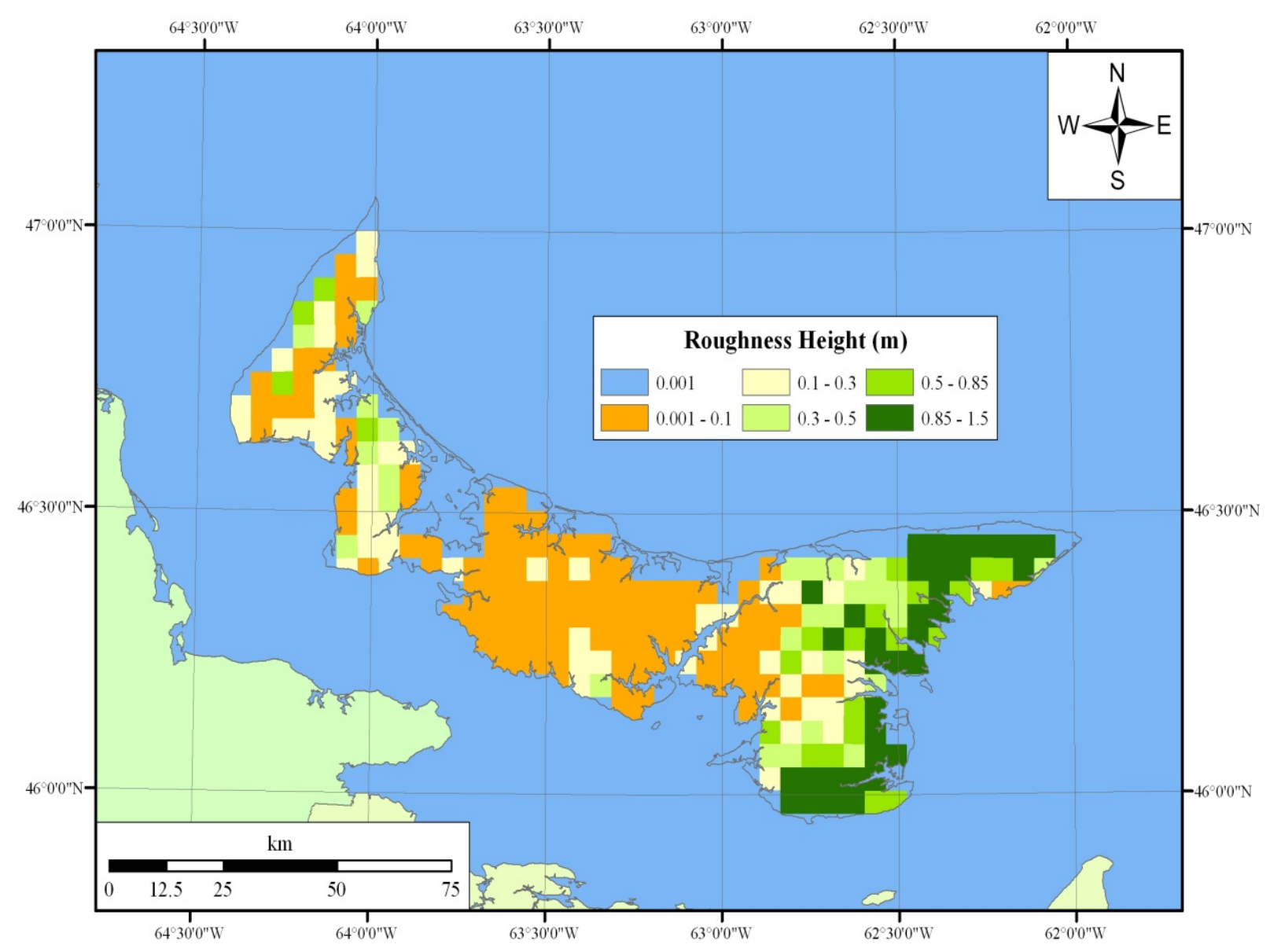


Figure 4. Mesoscale roughness height for CWEAHD scenario.

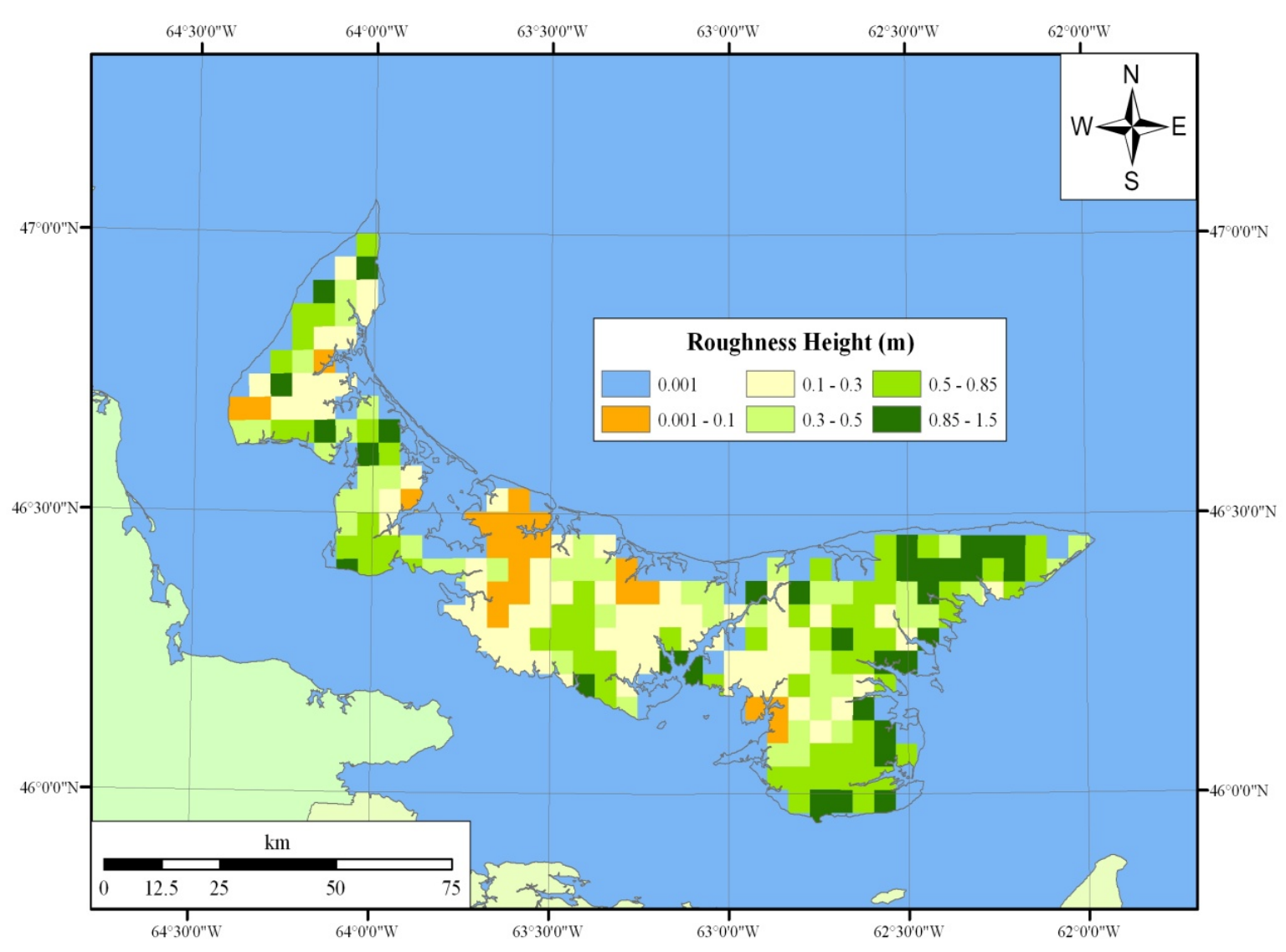

Figure 5. Mesoscale roughness height bias between CWEAHD and CWEA scenarios.

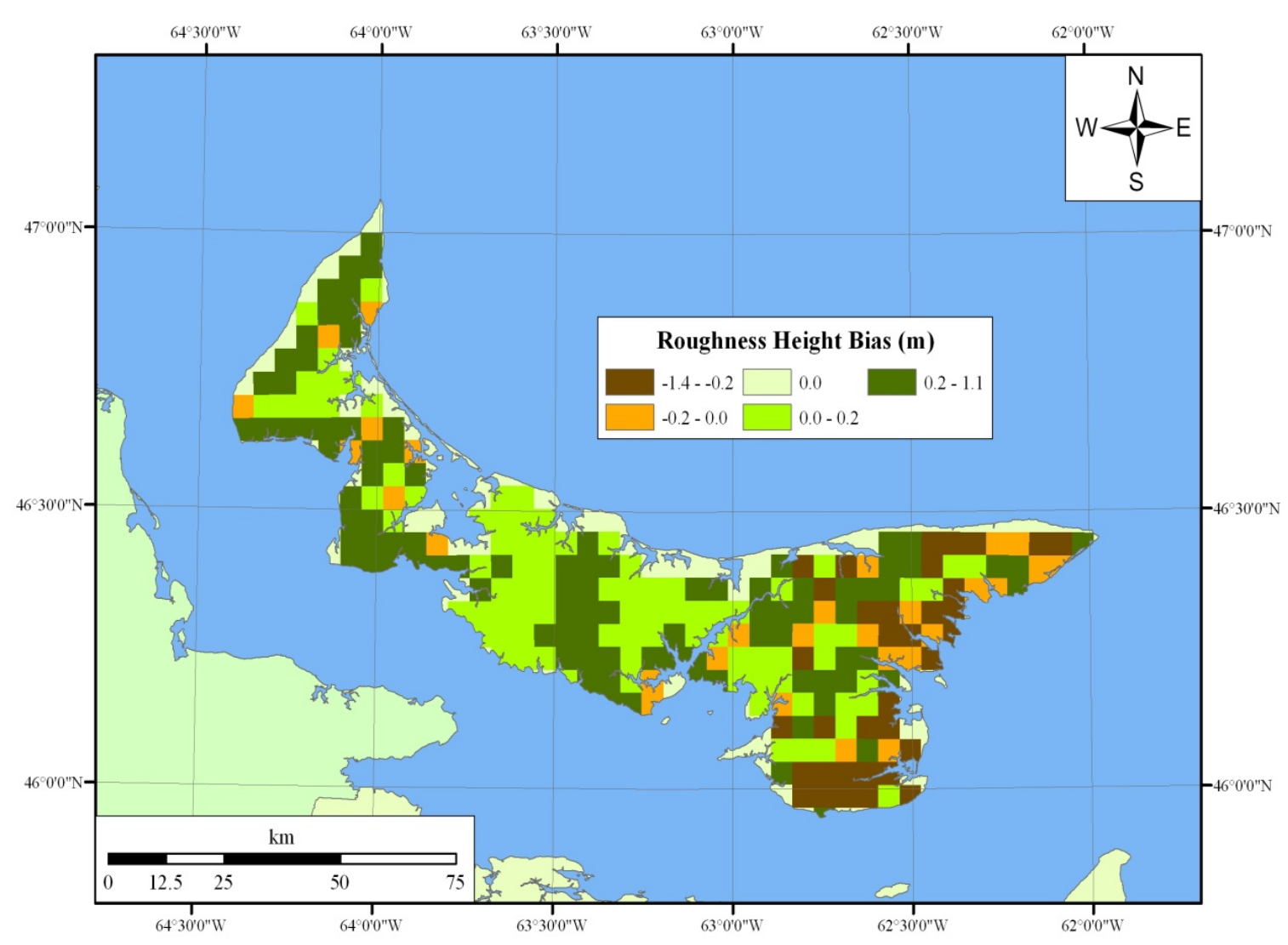


For its part, Figure 6 shows the mesoscale roughness heights map used as input of WAsP to transform CWEA datasets into "regional wind climate" datasets in the CWEA-WAsP scenario. Comparing Figure 6 with Figures 3 and 4, it can be seen that the WAsP mesoscale roughness values are between the CWEA and CWEAHD scenarios for the whole province (notably in the central part) except in the eastern quarter and places where the forest is denser. This is primarily due to the different roughness height values attributed by each model to the forest class; to this end, it can be seen in Table 2 that the forest class has a roughness height value of 1.5 in the CWEA-MsMicro and CWEAHD-MsMicro scenarios compared to 0.8 in the CWEA-WAsP scenario. Furthermore, due to the logarithmic mean used to average roughness data, all meshes of the WAsP mesoscale roughness map located on the coastline feature values slightly above $0.001 \mathrm{~m}$ which is almost never the case for the data processed by Anemoscope.

Figure 6. Mesoscale roughness height for CWEA-WAsP scenarios.

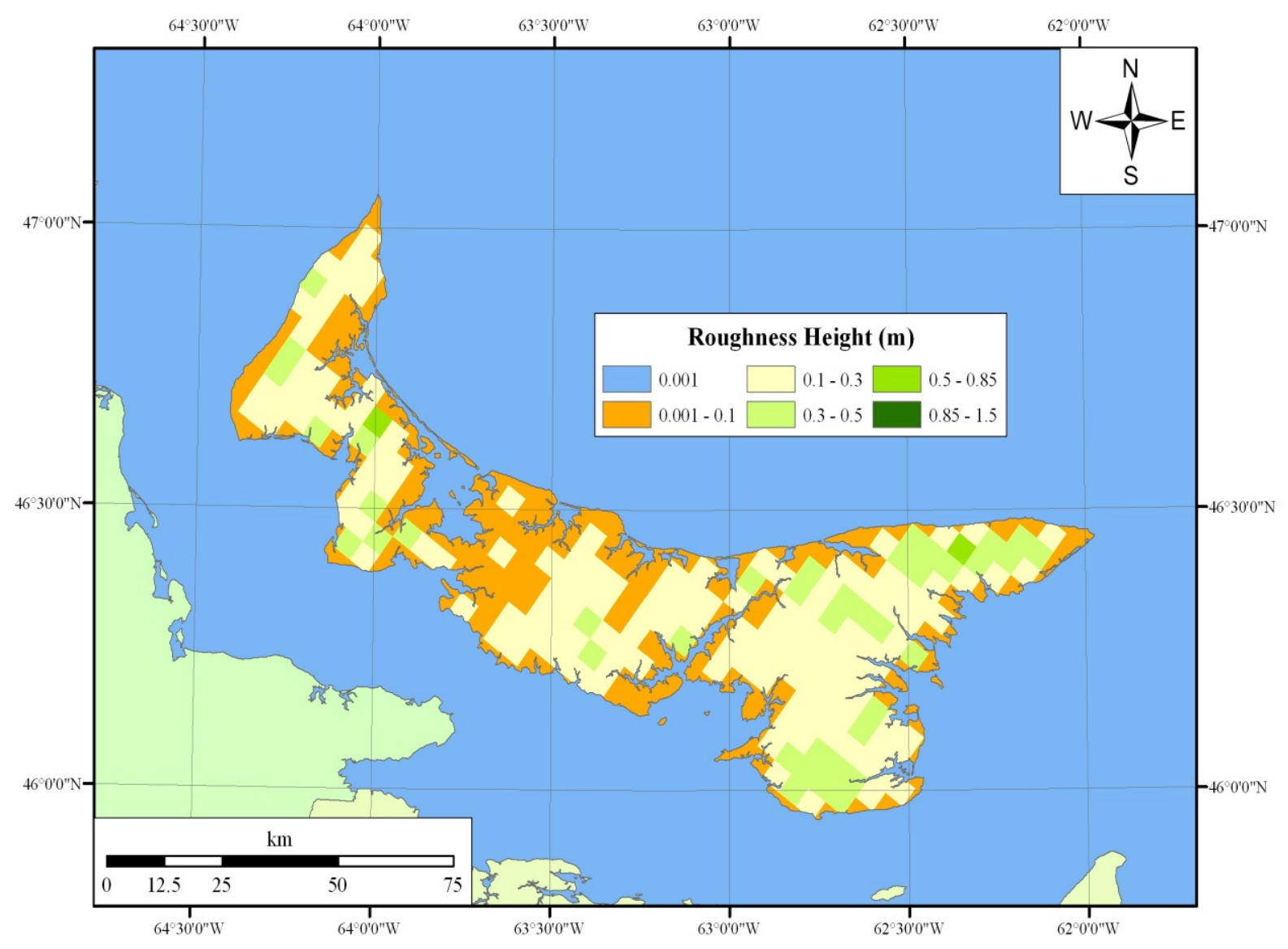

The roughness heights for the microscale CWEA-MsMicro/CWEAHD-MsMicro and CWEA-WAsP scenarios are shown in Figures 7 and 8, respectively. In comparing both scenarios, Figures 7 and 8, it can be seen that the distribution of the roughness height is roughly the same; however, the CWEA-MsMicro/CWEAHD-MsMicro scenarios have higher roughness height values than the CWEA-WAsP scenario due to their respective land cover roughness classification, and most notably, because of the roughness value associated with the forest class. 
Figure 7. Microscale roughness height for CWEA-MsMicro and CWEAHD-MsMicro scenarios.

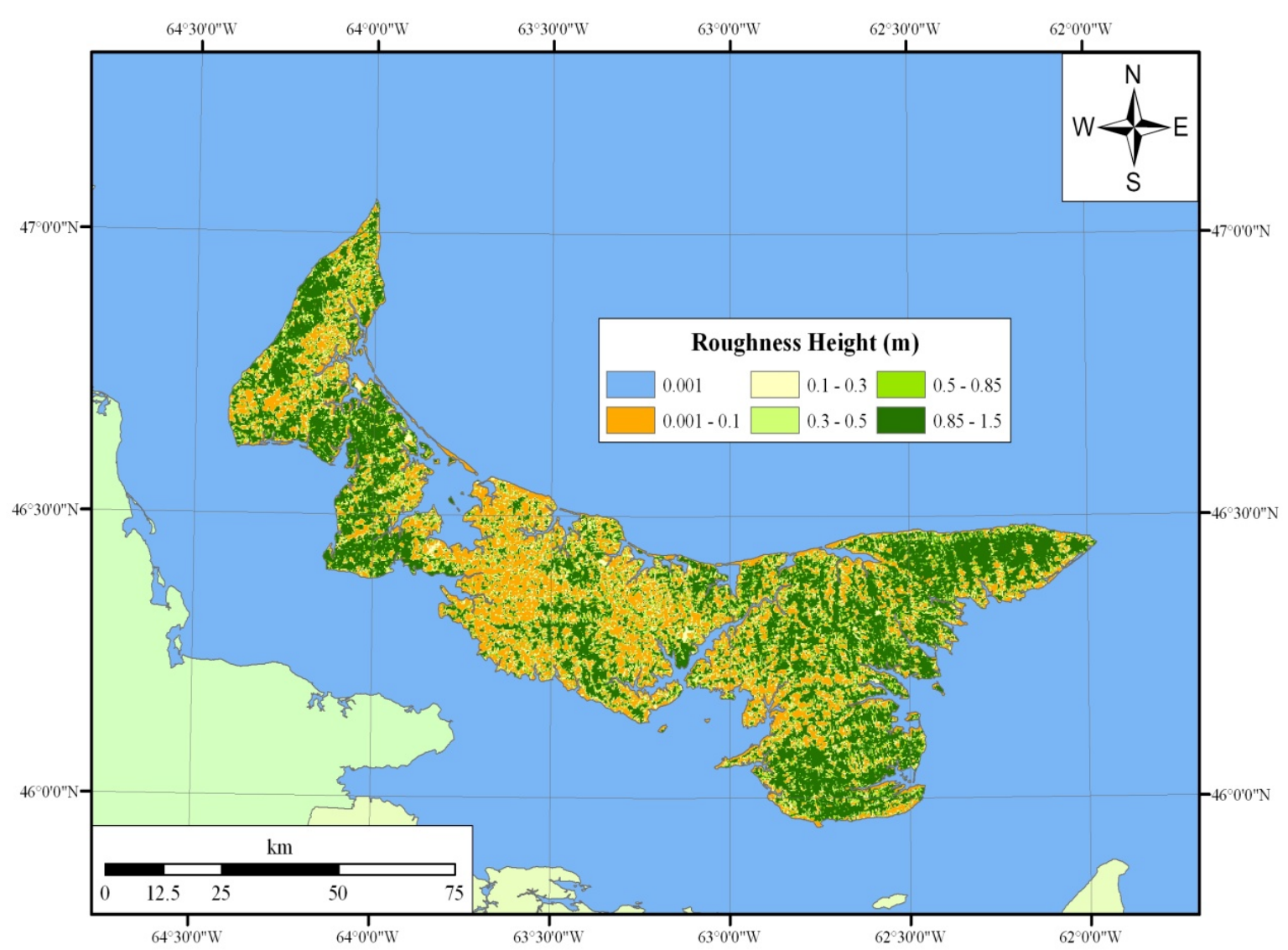

Figure 8. Microscale roughness height for CWEA-WAsP scenario.

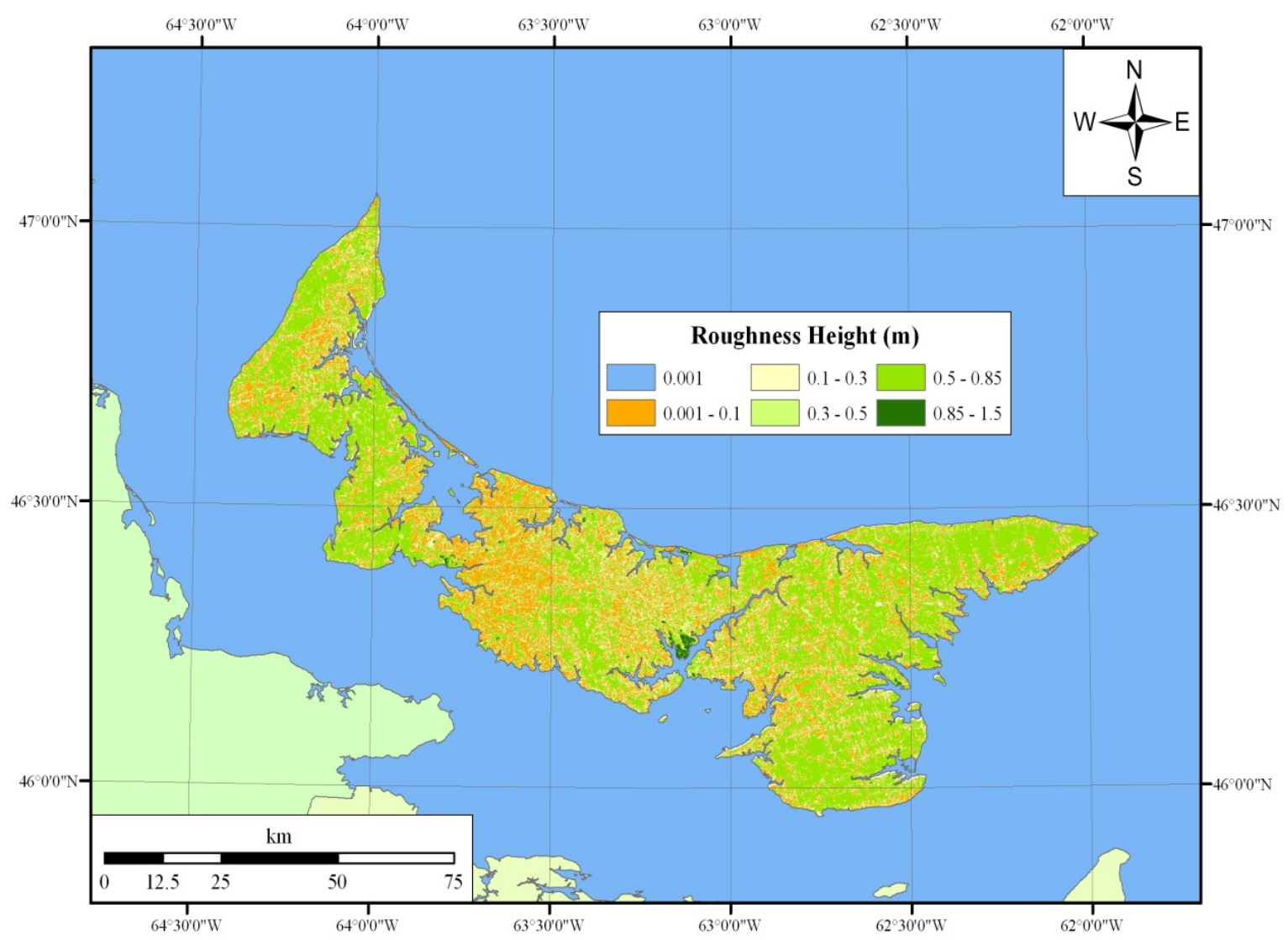


This is also evident in the roughness height bias between the CWEA-MsMicro/ CWEAHD-MsMicro and CWEA-WAsP scenarios, Figure 9. This bias distribution and amplitude appears to be similar to the differences between the CWEAHD and WAsP mesoscale roughness maps shown in Figures 4 and 6. Indeed, the same high resolution land cover dataset is used as input along with the same logarithmic means approach to produce the mesoscale and microscale roughness maps for the CWEA-WAsP scenario shown in Figures 6 and 8, respectively. As a result, the transformations of the CWEA wind climate dataset into "regional wind climate" datasets, which used the mesoscale roughness maps shown in Figure 6, remains consistent with the use of the latter data to produce wind resource maps, based on the microscale roughness map shown in Figure 8.

Figure 9. Microscale roughness height bias between CWEA-MsMicro/CWEAHDMsMicro and CWEA-WAsP scenarios.

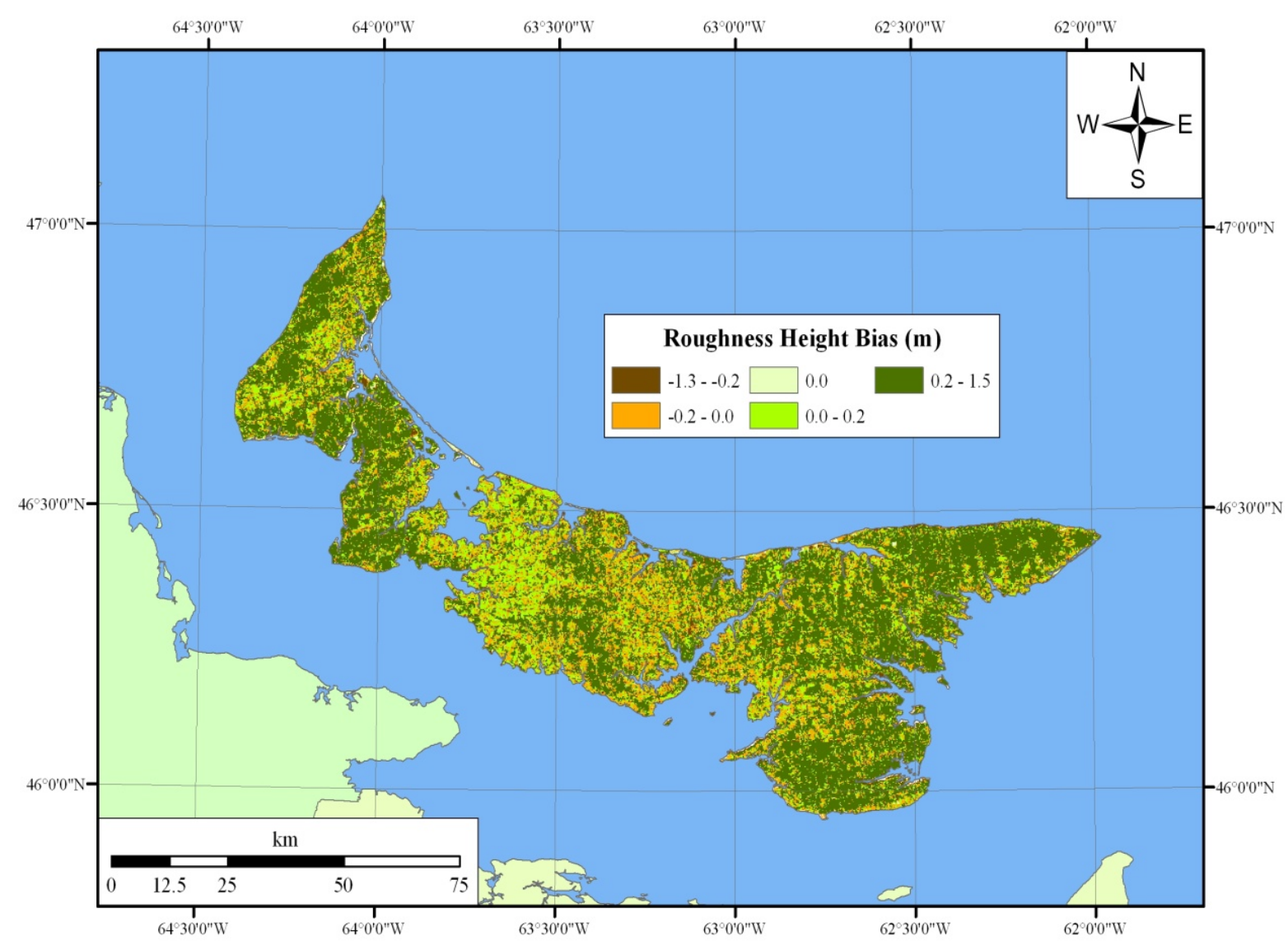

\subsection{Met Tower and Validation}

In this work, wind resource maps are produced without reference to any surface wind data. As a result, the primary purpose of the surface station data is for the validation of the numerically obtained wind resource maps.

During the period of spring 2004 to fall 2007, in an effort to undertake a province wide wind assessment program, the Prince Edward Island Energy Corporation installed a series of ten $50 \mathrm{~m}$ met towers at various locations in the province, Figure 10. The dataset from the PEI Wind Assessment (PEIWA) project was provided by the Prince Edward Island Energy Corporation [34]. It is important to note that these met towers had a wind energy assessment purpose, i.e., they were located in well 
exposed sites and had regular data collection with a data quality inspection and a dataset completion. The only shortcoming of this dataset is the relatively short time period for most of the records. Because of the seasonal cycle, a met tower retained in this study feature at least 8 months of records in order to be considered as representative of the wind resource $[1,6,23]$.

Figure 10. Met tower locations of the PEI Wind Assessment project.

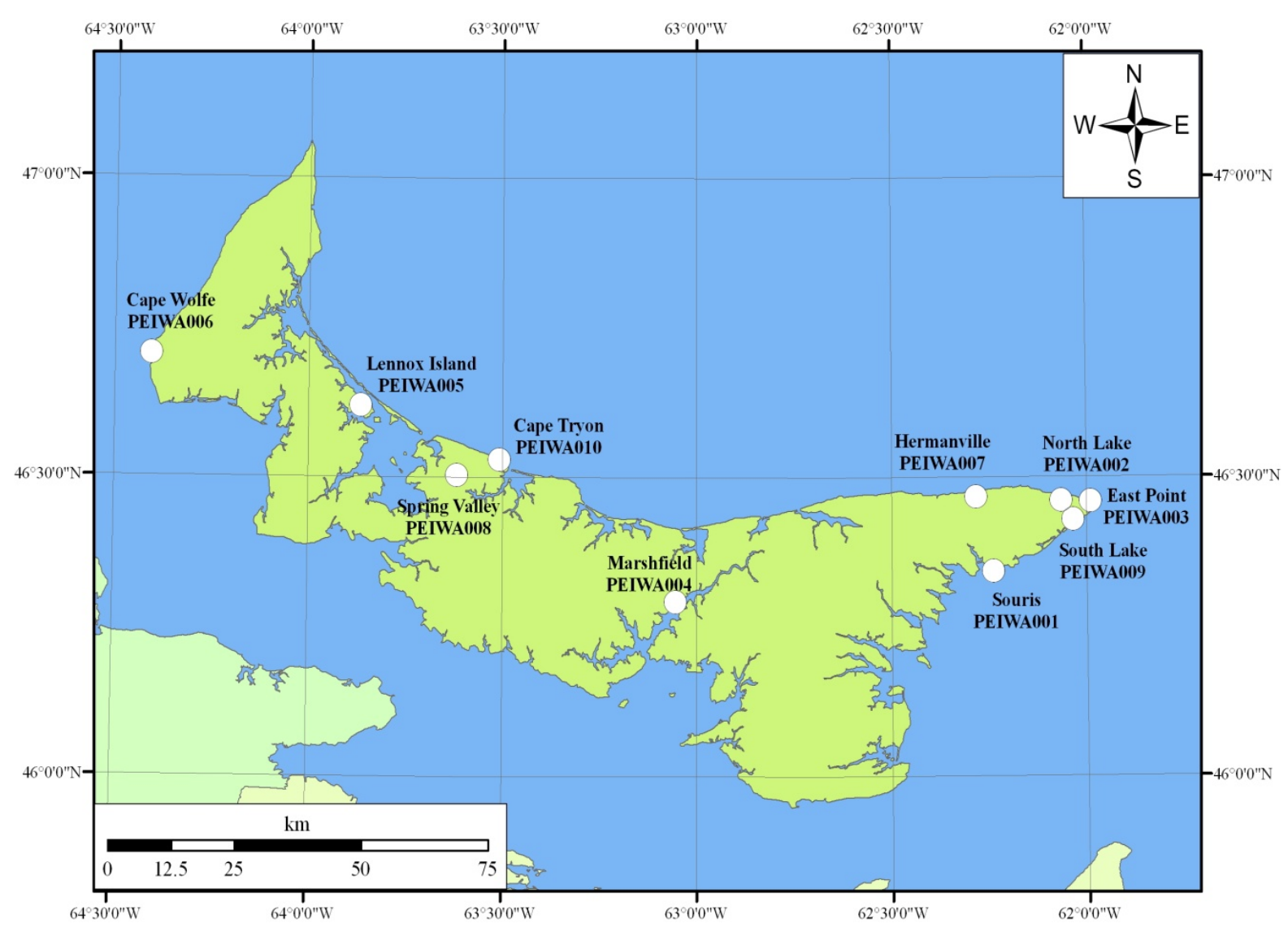

As a summary, Table 3 shows the main properties of the ten stations available in this study. It is to note that most of the met towers have a mean wind speed equal to or above $7 \mathrm{~m} / \mathrm{s}$. Only the Marshfield station has an observed mean wind speed of near $6 \mathrm{~m} / \mathrm{s}$. This latter station is in the centre of the island, on a south east descending side of a hill (most frequent winds are from west/south west and the north), while all other stations are on or close to the shore line. It is also the station from the PEIWA project that has the shortest period of records ( 8 months). During the PEIWA project, it became clear that this met tower was not installed in a well exposed site and was removed after 8 months of records. Since the recording period is from June to early February, the windy spring season is not captured in the dataset. For these reasons, the dataset from the Marshfield station is rejected from the comparison analysis. 
Table 3. Summary of PEIWA met tower properties.

\begin{tabular}{clcccccc}
\hline ID & Location Name & Start & End & $\begin{array}{c}\text { Hagl } \\
(\mathbf{m})\end{array}$ & $\begin{array}{c}\text { X } \\
\text { UTM } \\
\mathbf{2 0}\end{array}$ & $\begin{array}{c}\text { Y } \\
\text { UTM }\end{array}$ & $\begin{array}{c}\text { Observed Mean } \\
\text { Wind Speed } \\
(\mathbf{m} / \mathbf{s})\end{array}$ \\
\hline PEIWA001 & Souris & $30 / 06 / 2004$ & $30 / 06 / 2005$ & 50 & 558500 & 5132600 & 7.40 \\
PEIWA002 & North Lake & $31 / 01 / 2004$ & $31 / 01 / 2005$ & 50 & 571778 & 5145767 & 7.59 \\
PEIWA003 & East Point & $17 / 12 / 2004$ & $17 / 12 / 2005$ & 50 & 577550 & 5145650 & 8.09 \\
PEIWA004 & Marshfield & $31 / 05 / 2004$ & $02 / 02 / 2005$ & 50 & 495800 & 5126700 & 6.15 \\
PEIWA005 & Lennox Island & $30 / 06 / 2004$ & $30 / 06 / 2005$ & 50 & 433700 & 5163400 & 6.75 \\
PEIWA006 & Cape Wolf & $07 / 01 / 2004$ & $07 / 01 / 2005$ & 50 & 392469 & 5173337 & 7.68 \\
PEIWA007 & Hermanville & $28 / 02 / 2005$ & $28 / 02 / 2006$ & 50 & 555000 & 5146300 & 7.28 \\
PEIWA008 & Spring Valley & $30 / 06 / 2004$ & $30 / 06 / 2005$ & 50 & 452555 & 5150304 & 6.86 \\
PEIWA009 & South Lake & $31 / 01 / 2006$ & $31 / 01 / 2007$ & 50 & 574164 & 5142328 & 6.71 \\
PEIWA010 & Cape Tryon & $31 / 09 / 2005$ & $31 / 09 / 2006$ & 50 & 461040 & 5153199 & 8.24 \\
\hline
\end{tabular}

The difference between the observed wind speeds and the computed wind speeds, namely the model error, can come from systematic errors or from random errors. These latter errors are generally considered random, normally distributed and independent from station to station [23]. Several statistical criteria can thus be used to evaluate those two errors:

(1) The model bias or Mean Relative Error (MRE) corresponds to systematic errors. It is estimated as the average error of all the stations.

(2) The Mean Absolute Error (MAE) gives information on both systematic and random errors. It is computed as the average absolute error of all the stations.

(3) The Root Mean Squared Error (RMSE) also reflects systematic and random errors. It is the root of the average squared error of all the stations.

(4) Finally, the Standard Deviation Error (SDE) is an estimate for the standard deviation of the error distribution (which is considered normal). Thus, only random errors contribute to the SDE.

Normalized versions of these four indicators can also be computed (NMRE, NMAE, NRMSE and NSDE, respectively) by normalizing with the mean wind speed from all the stations. Those basic criteria illustrate the prediction error, and it is to note that, since RMSE and MAE include information of both systematic and random errors, they better represent the overall error. Statistically, the value of the MRE and MAE are associated with the first moment of the prediction error and the value of the RMSE and SDE are associated with the second order moment. As a result, the information given by the MRE and MAE is directly related to the differences in mean wind speeds while the one provided by the RMSE and SDE is related to the variance of the predicted error. The latter measures are thus linked with the scatter of the comparison results and large prediction errors have the largest effect. Thus, the RMSE is a more strict criteria than the MAE and it is usually considered as the best indicator of model error [23]. Finally, it is to be noted that the larger the dataset used in the comparison, the more representative are these criteria. While only nine stations were available in this study, these criteria are nevertheless used since they offer the strictest comparison. 


\section{Results}

\subsection{Mesoscale Results}

The mesoscale mean wind speeds results at $50 \mathrm{~m}$ agl for both mesoscale CWEA and CWEAHD scenarios are shown in Figures 11 and 12, respectively. For its part, Figure 13 shows the mesoscale mean wind speed bias between the CWEAHD and the CWEA scenarios at $50 \mathrm{~m}$ agl. From Figure 13, it can be seen that the mean wind speeds are generally lower in the CWEAHD scenario. For its part, Figure 14 shows the probability density function of the mean wind speed bias between the CWEAHD and the CWEA scenarios at $50 \mathrm{~m}$ agl. The latter is usually assumed to follow a normal distribution (due to the random nature of the bias). In the present case, it is centered on the mean of the bias, $-0.21 \mathrm{~m} / \mathrm{s}$ with a standard deviation of $0.34 \mathrm{~m} / \mathrm{s}$. This further confirms the lower mean wind speeds of the CWEAHD scenario. However, probably because of a lack of sample points at the mesoscale resolution over the study area, the obtained mean wind speed bias departs from the theoretical normal.

Figure 11. Mesoscale wind resource map at $50 \mathrm{~m}$ agl at a resolution of $5 \mathrm{~km}$ : CWEA scenario.

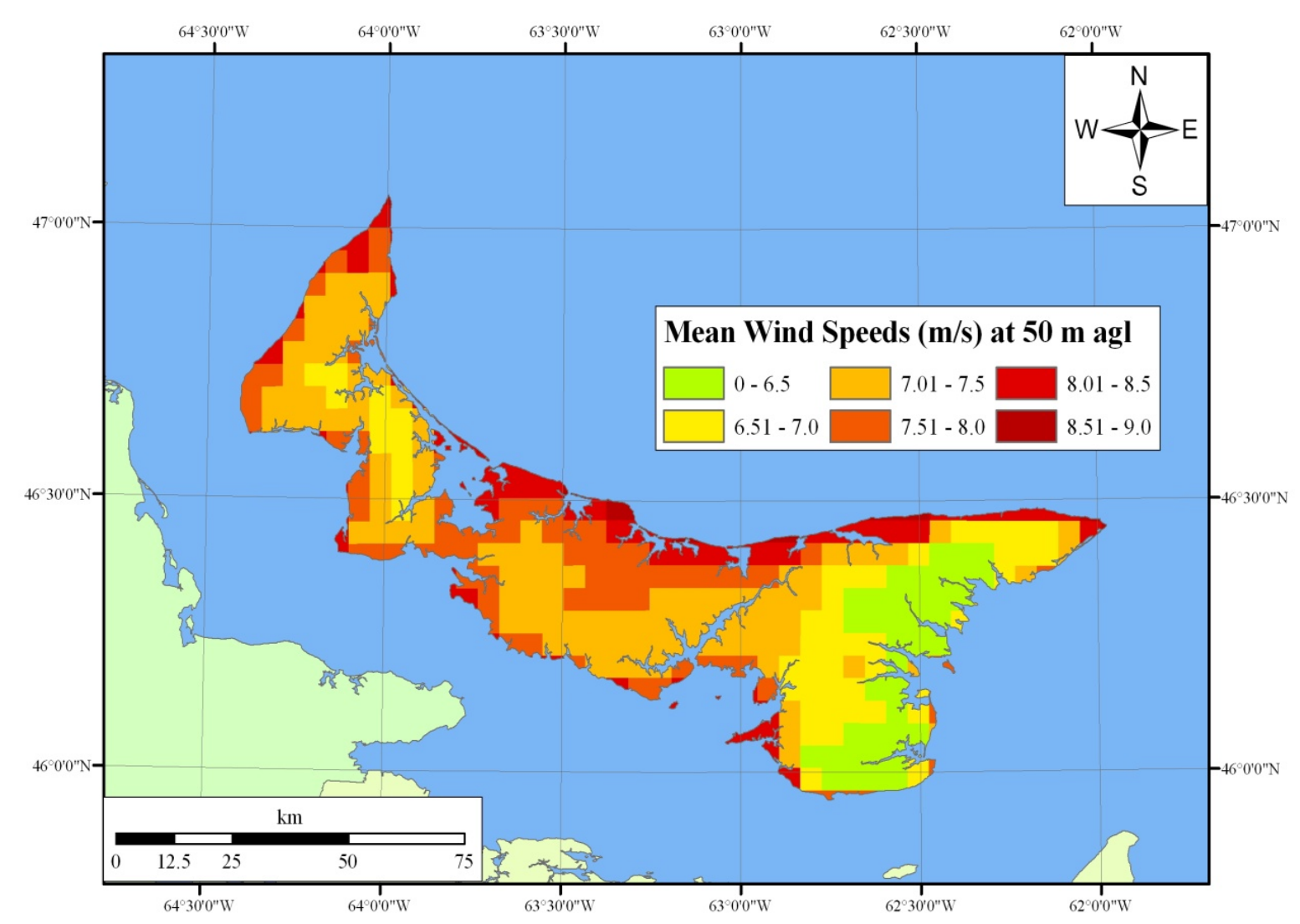


Figure 12. Mesoscale wind resource map at $50 \mathrm{~m}$ agl at a resolution of $5 \mathrm{~km}$ : CWEAHD scenario.

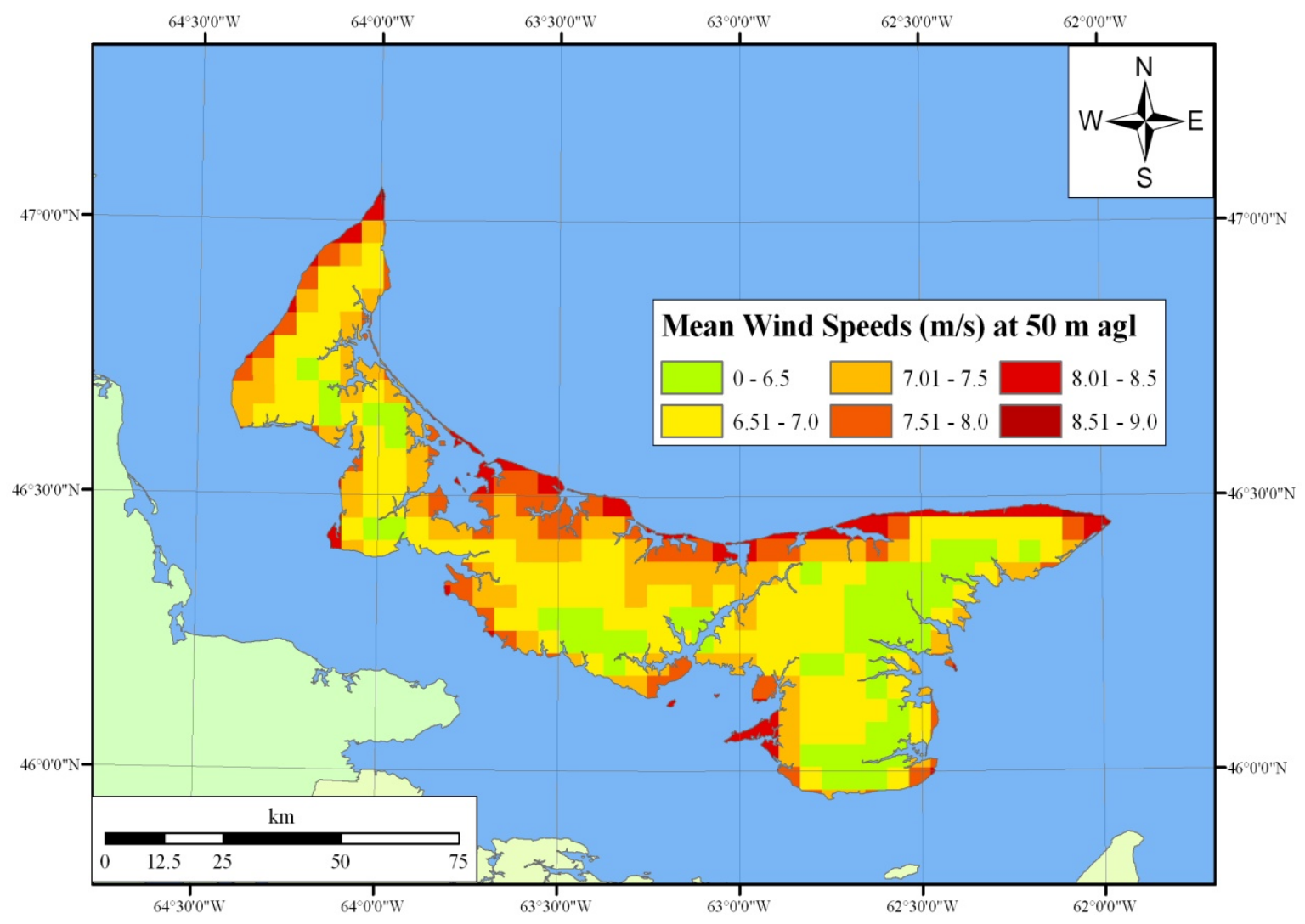

Figure 13. Mesoscale wind bias between CWEAHD and CWEA scenarios at $50 \mathrm{~m}$ agl.

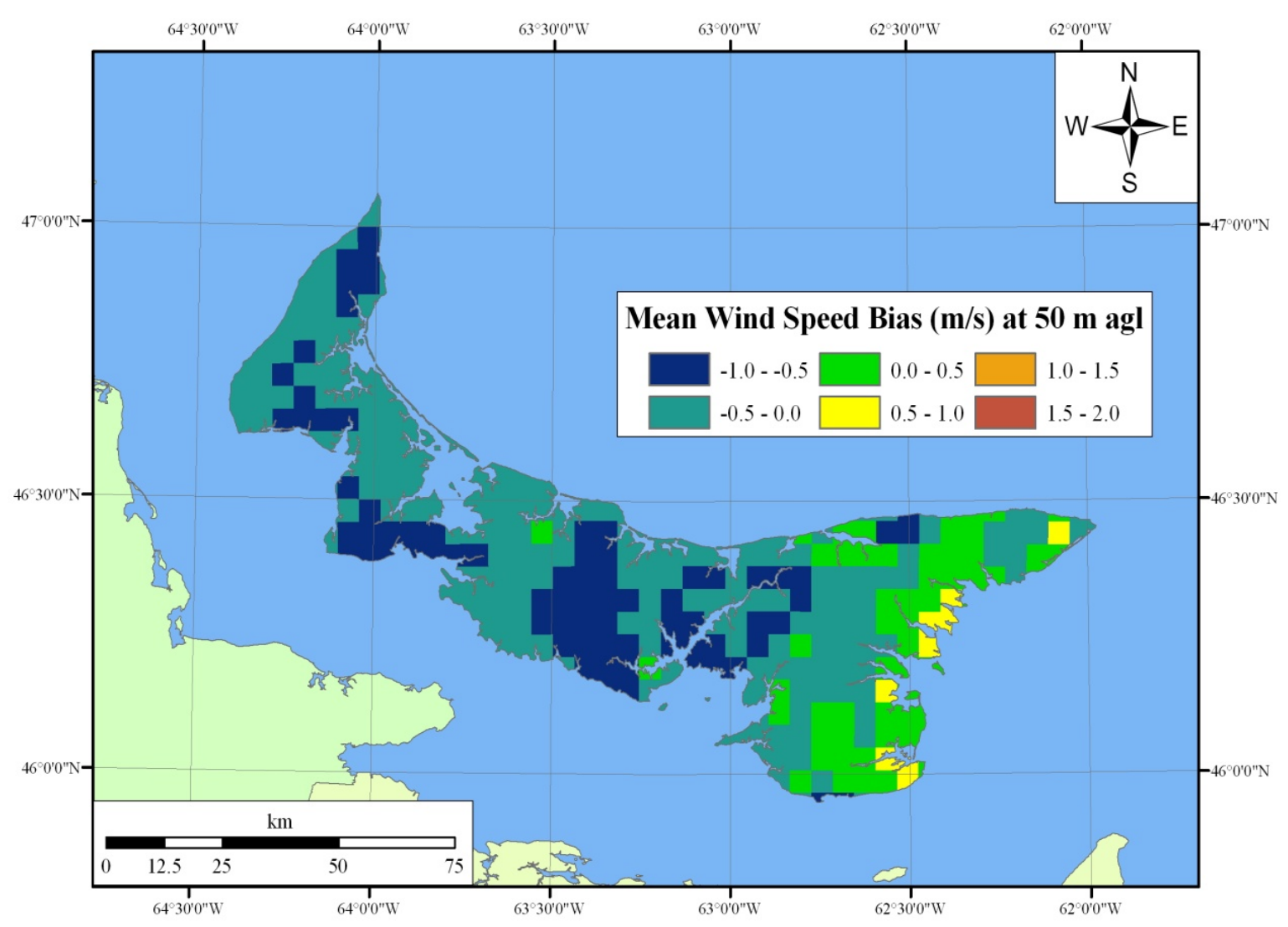


Figure 14. Probability density function of the mesoscale mean wind speed bias between CWEAHD and CWEA scenarios at $50 \mathrm{~m}$ agl.

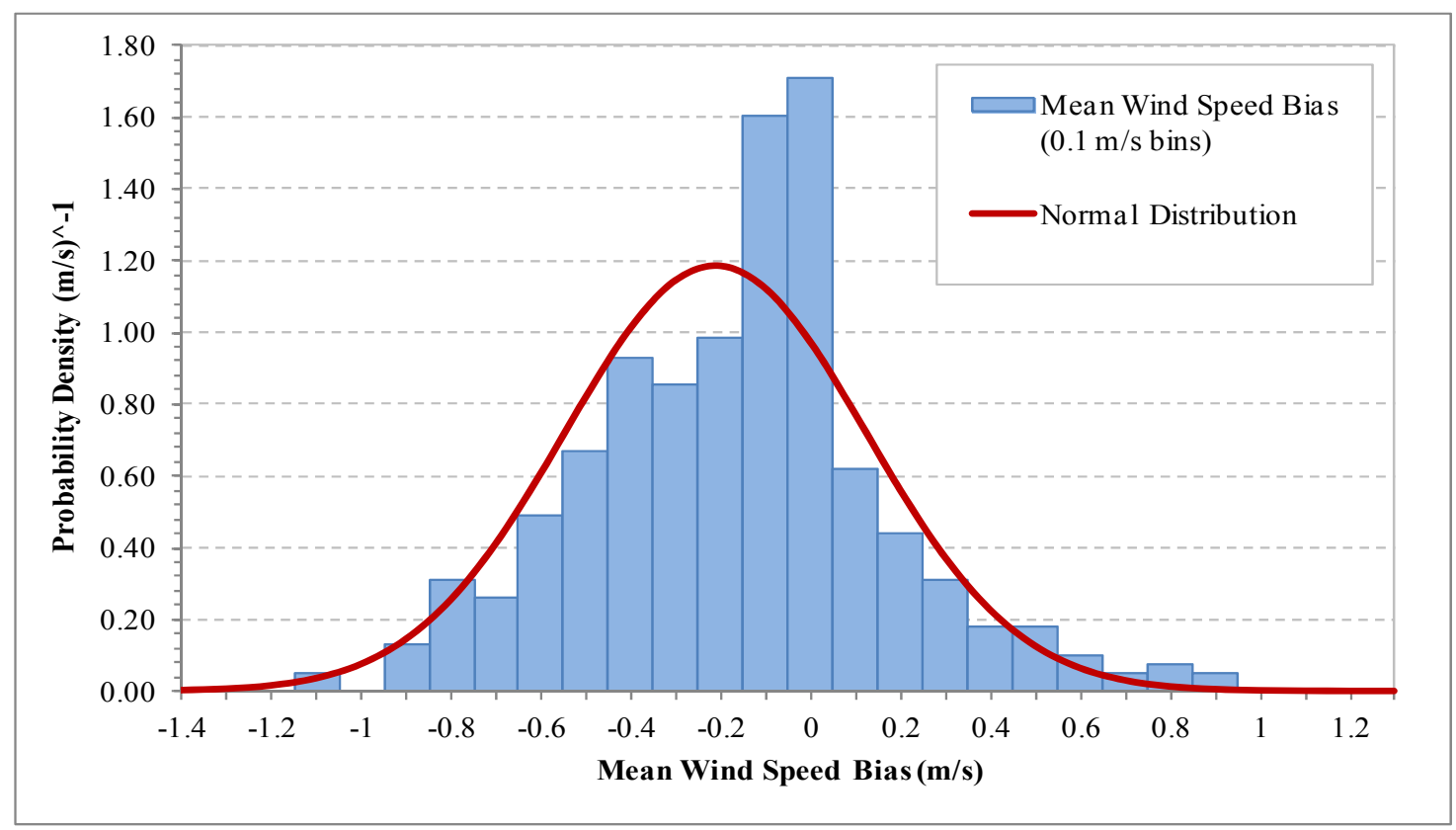

These differences in the mesoscale results can be explained by the higher roughness associated with the up to date higher resolution land cover dataset used in the CWEAHD scenario, which translates to lower wind speeds for the corresponding scenario. Indeed, mean wind speed differences mostly correspond to the roughness bias between CWEA and CWEAHD shown in Figure 5. As an example, the mean wind speeds are significantly lower (by 0.51 to $1.5 \mathrm{~m} / \mathrm{s}$ ) in the urban area of the City of Charlottetown corresponding to a higher roughness in the CWEAHD scenario in comparison with the CWEA scenario; this also seems to suggest that the province's urban areas are not well captured in the low resolution USGS land cover dataset provided with Anemoscope (from which it is almost absent as seen in Figure 3).

\subsection{Microscale Results}

Figures 15-17 show the microscale mean wind speeds results at $50 \mathrm{~m}$ agl for the CWEA-MsMicro, CWEAHD-MsMicro and CWEA-WAsP scenarios, respectively. It can be seen that the overall mean wind speeds are generally lower in the CWEA-WAsP scenario, whereas the overall mean wind speeds are highest in the CWEA-MsMicro scenario. By comparing the Figure 15 through 17, it can be seen that the difference in mean wind speeds are primarily located in the central and western sections of the province. 
Figure 15. Microscale wind resource map at $50 \mathrm{~m}$ agl at a resolution of $200 \mathrm{~m}$ : CWEA-MsMicro scenario.

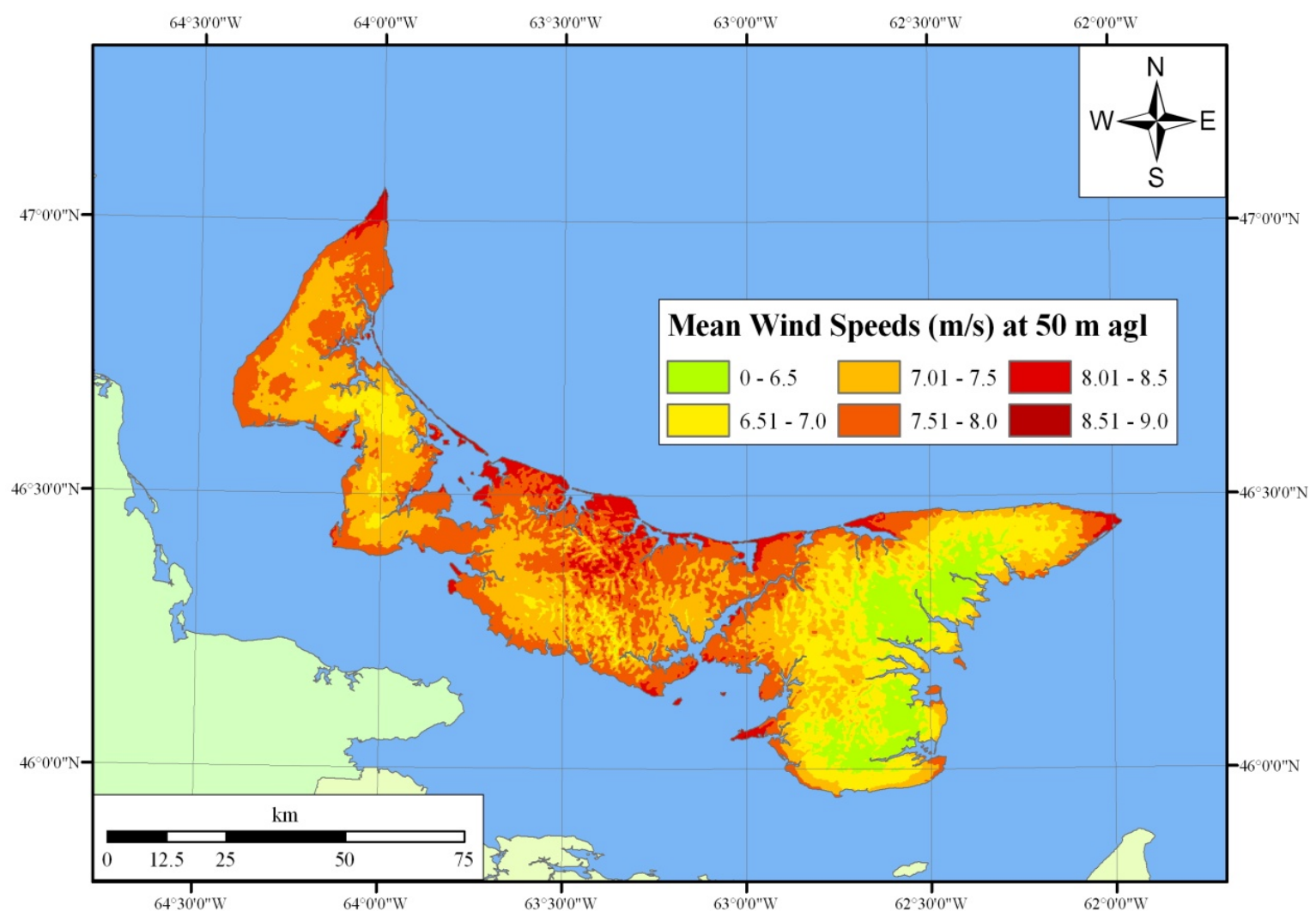

Figure 16. Microscale wind resource map at $50 \mathrm{~m}$ agl at a resolution of $200 \mathrm{~m}$ : CWEAHD-MsMicro scenario.

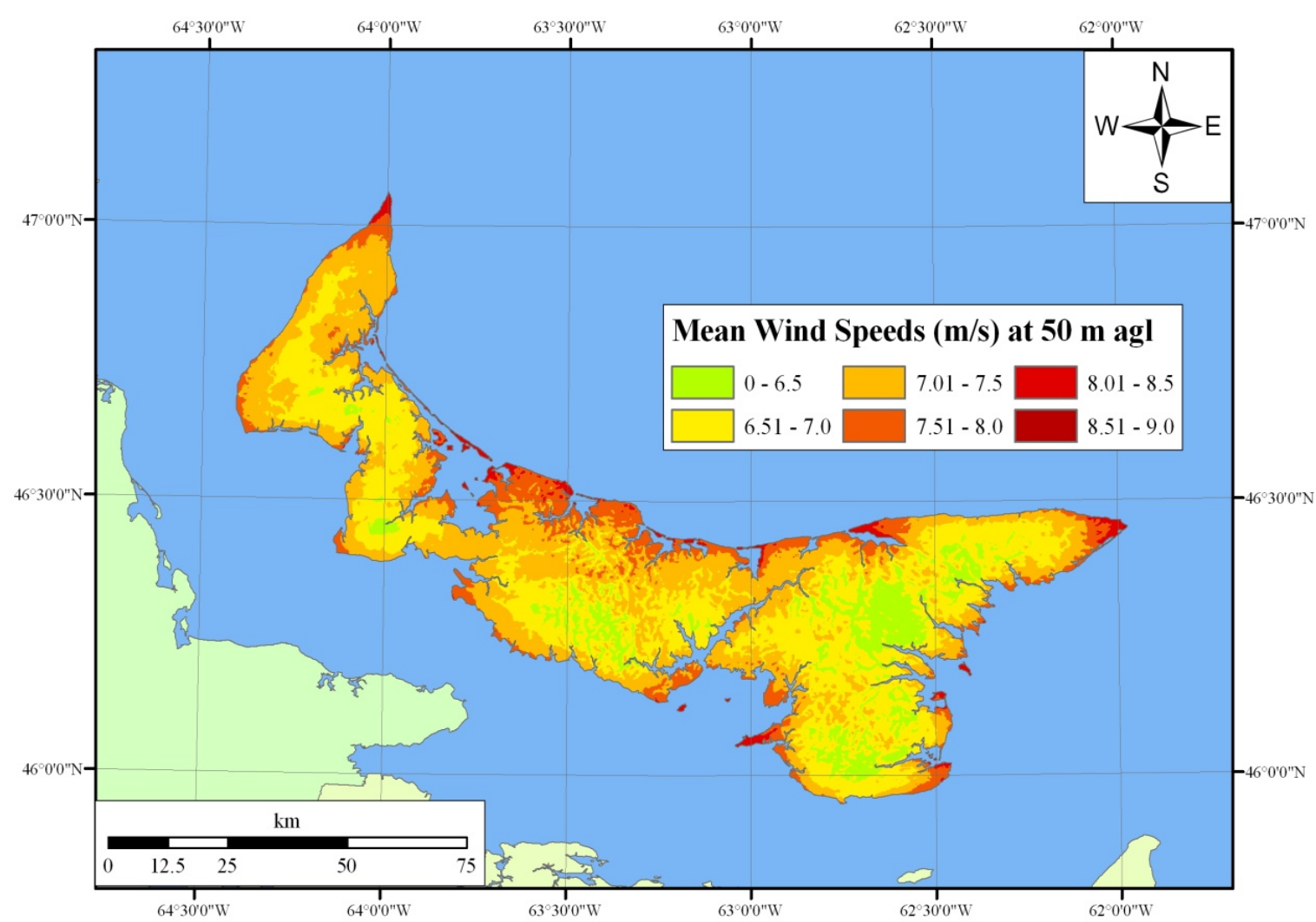


Figure 17. Microscale wind resource map at $50 \mathrm{~m}$ agl at a resolution of $200 \mathrm{~m}$ : CWEA-WAsP scenario.

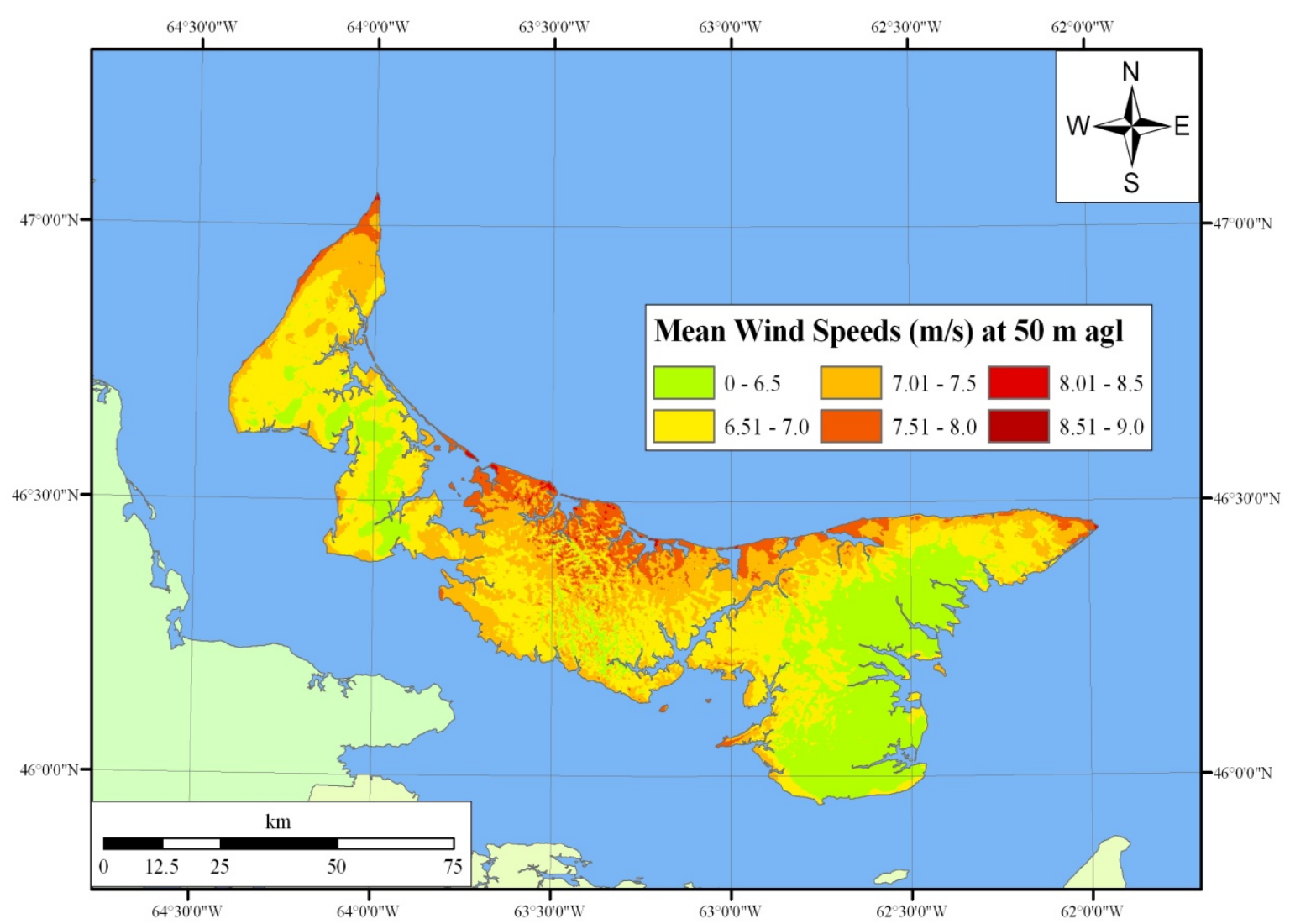

For its part, Figure 18 shows the microscale mean wind speed difference between the CWEAHD-MsMicro and the CWEA-MsMicro scenarios at $50 \mathrm{~m}$ agl. From Figure 18, it can be seen that in the CWEAHD-MsMicro scenario, the mean wind speeds are generally 0 to $0.5 \mathrm{~m} / \mathrm{s}$ lower than in the CWEA-MsMicro scenario. Further, as was the case in the mesoscale analysis, in comparison to the CWEA-MsMicro scenario, the CWEAHD-MsMicro scenario exhibits mean wind speeds lower by 0.5 to $1.0 \mathrm{~m} / \mathrm{s}$ in the central section and in some areas in the western section of the province. As a summary of these remarks, Figure 19 shows the probability density function of the mean wind speed bias between the microscale CWEAHD-MsMicro and CWEA-MsMicro scenarios at $50 \mathrm{~m}$ agl; where it can be seen that the bias tends to some extent towards a normal distribution centered on the mean of the bias, $-0.22 \mathrm{~m} / \mathrm{s}$, and having a standard deviation of $0.26 \mathrm{~m} / \mathrm{s}$. These values are also similar to those of the bias between the mesoscale CWEAHD and CWEA scenarios. As a result, and since the same topography and land cover datasets are used in the CWEA-MsMicro and the CWEAHD-MsMicro scenarios, the differences in mean wind speeds between these two scenarios can be fully attributed to the mesoscale results used as input data in the microscale model. In that sense, it is interesting to note the smoothness of the mean wind speed bias between these corresponding scenarios; microscale details are generally absent, while the distribution and shape of the mean wind speed bias are similar to the mesoscale bias between the CWEA and the CWEAHD scenarios (see Figure 13). 
Figure 18. Microscale wind bias between CWEAHD-MsMicro and CWEA-MsMicro scenarios at $50 \mathrm{~m}$ agl.

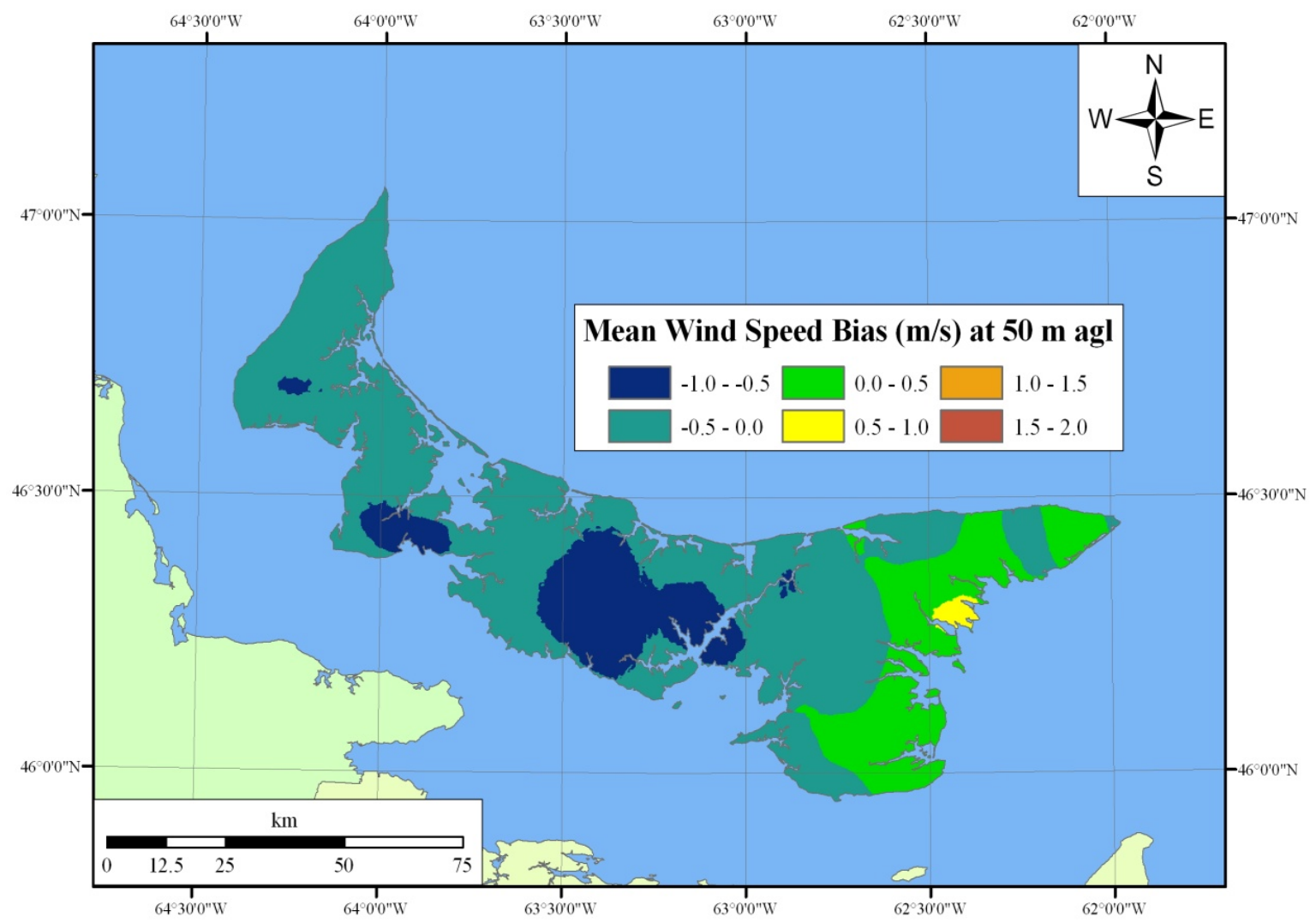

Figure 19. Probability density function of the microscale mean wind speed bias between CWEAHD-MsMicro and CWEA-MsMicro scenarios at $50 \mathrm{~m}$ agl.

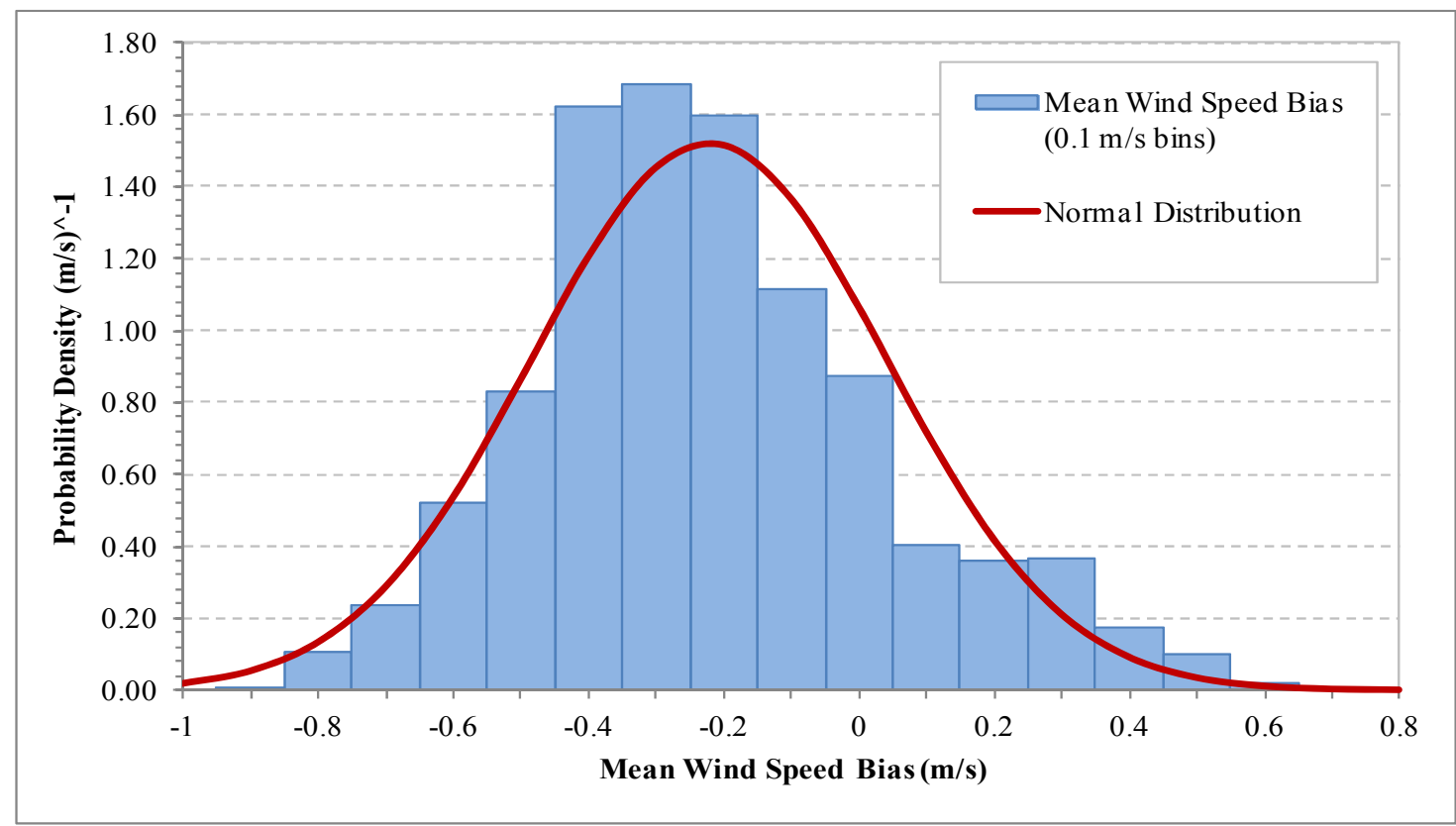

Figure 20 shows the microscale mean wind speed bias between the CWEA-MsMicro and the CWEA-WAsP scenarios at $50 \mathrm{~m}$ agl. From Figure 20, it can be seen that, for the majority of the province, in the CWEA-MsMicro scenario, the mean wind speeds are generally 0.0 to $0.50 \mathrm{~m} / \mathrm{s}$ faster 
(some areas between 0.5 and $1.0 \mathrm{~m} / \mathrm{s}$ ) than in the CWEA-WAsP scenario. In that sense, the probability density function of the mean wind speed bias between the CWEA-MsMicro and the CWEA-WAsP scenarios is shown in Figure 21; where it can be seen that the bias clearly follows a normal distribution centered on the mean of the bias, $0.55 \mathrm{~m} / \mathrm{s}$, and having a standard deviation of $0.28 \mathrm{~m} / \mathrm{s}$. The CWEA-WAsP approach thus leads to a notably slower wind speeds than the CWEA-MsMicro approach.

For its part, Figure 22 shows the microscale mean wind speed bias between the CWEAHD-MsMicro and the CWEA-WAsP scenarios at $50 \mathrm{~m}$ agl. From Figure 22, it can be seen that the differences are generally between -0.49 and $0.50 \mathrm{~m} / \mathrm{s}$ for most of the province, except along the eastern coast. The probability density function of the mean wind speed bias between these scenarios is shown in Figure 23; where it can be seen that the bias follows a normal distribution centered on the mean of the bias, $0.34 \mathrm{~m} / \mathrm{s}$, and having a standard deviation of $0.38 \mathrm{~m} / \mathrm{s}$. Consequently, as for the comparison of the CWEA-WAsP scenario with the CWEA-MsMicro scenario (albeit with a smaller bias), the mean wind speeds from the CWEA-WAsP scenario are also clearly lower than the ones obtained with the CWEAHD-MsMicro scenario.

Figure 20. Microscale wind bias between CWEA-MsMicro and CWEA-WAsP scenarios at $50 \mathrm{~m}$ agl.

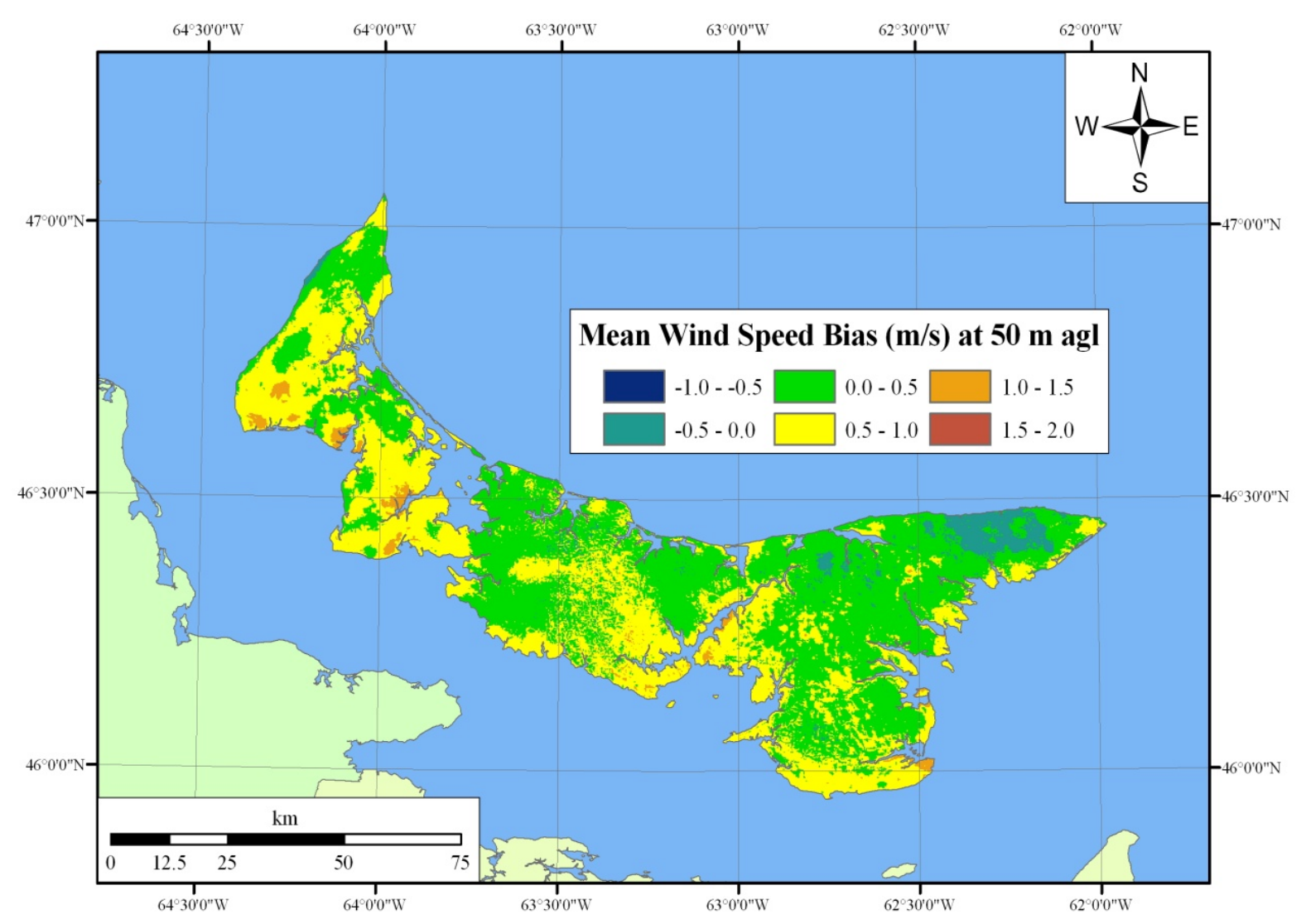


Figure 21. Probability density function of the microscale mean wind speed bias between CWEA-MsMicro and CWEA-WAsP scenarios at $50 \mathrm{~m}$ agl.

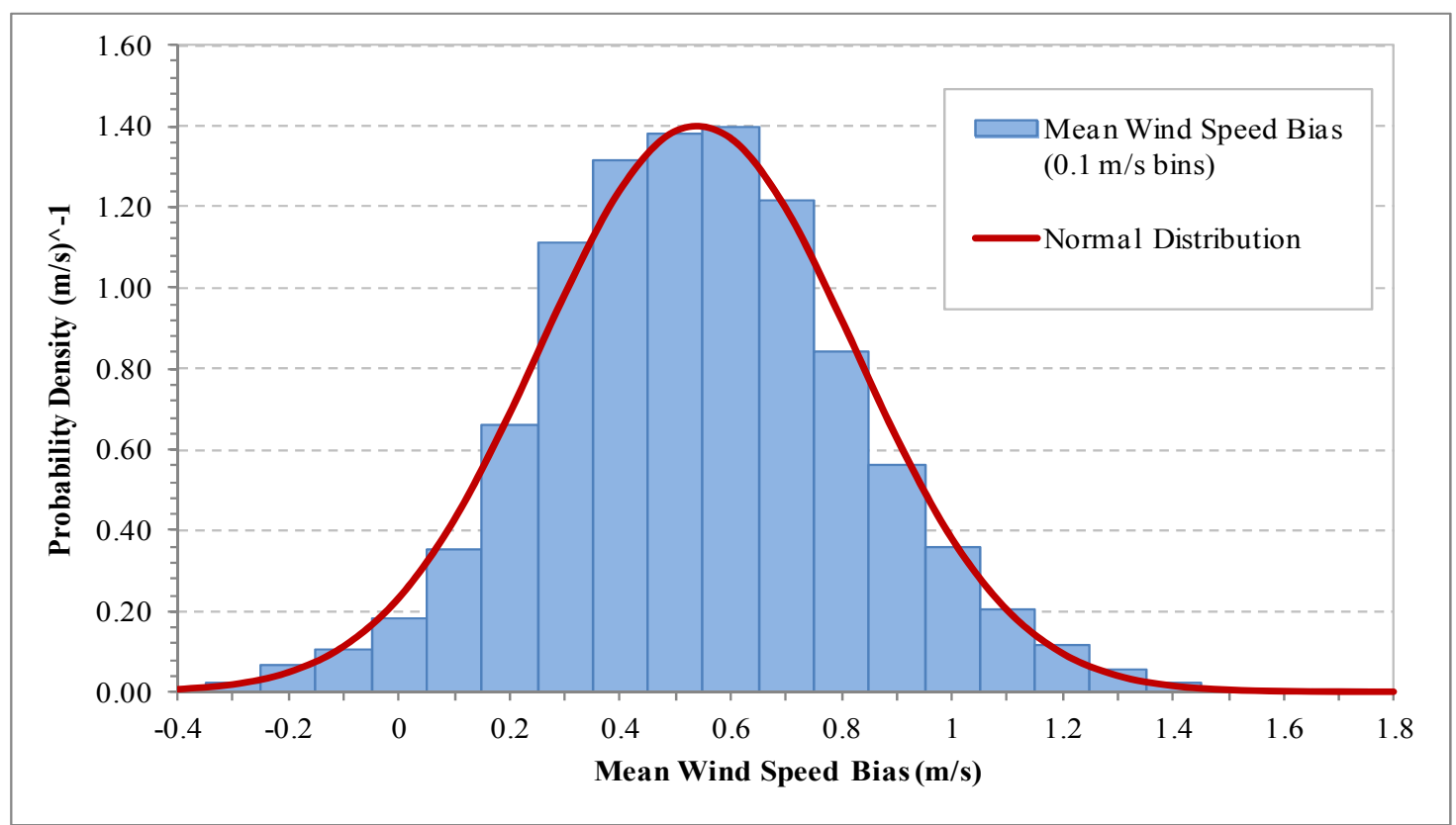

Figure 22. Microscale wind bias between CWEAHD-MsMicro and CWEA-WAsP scenarios at $50 \mathrm{~m}$ agl.

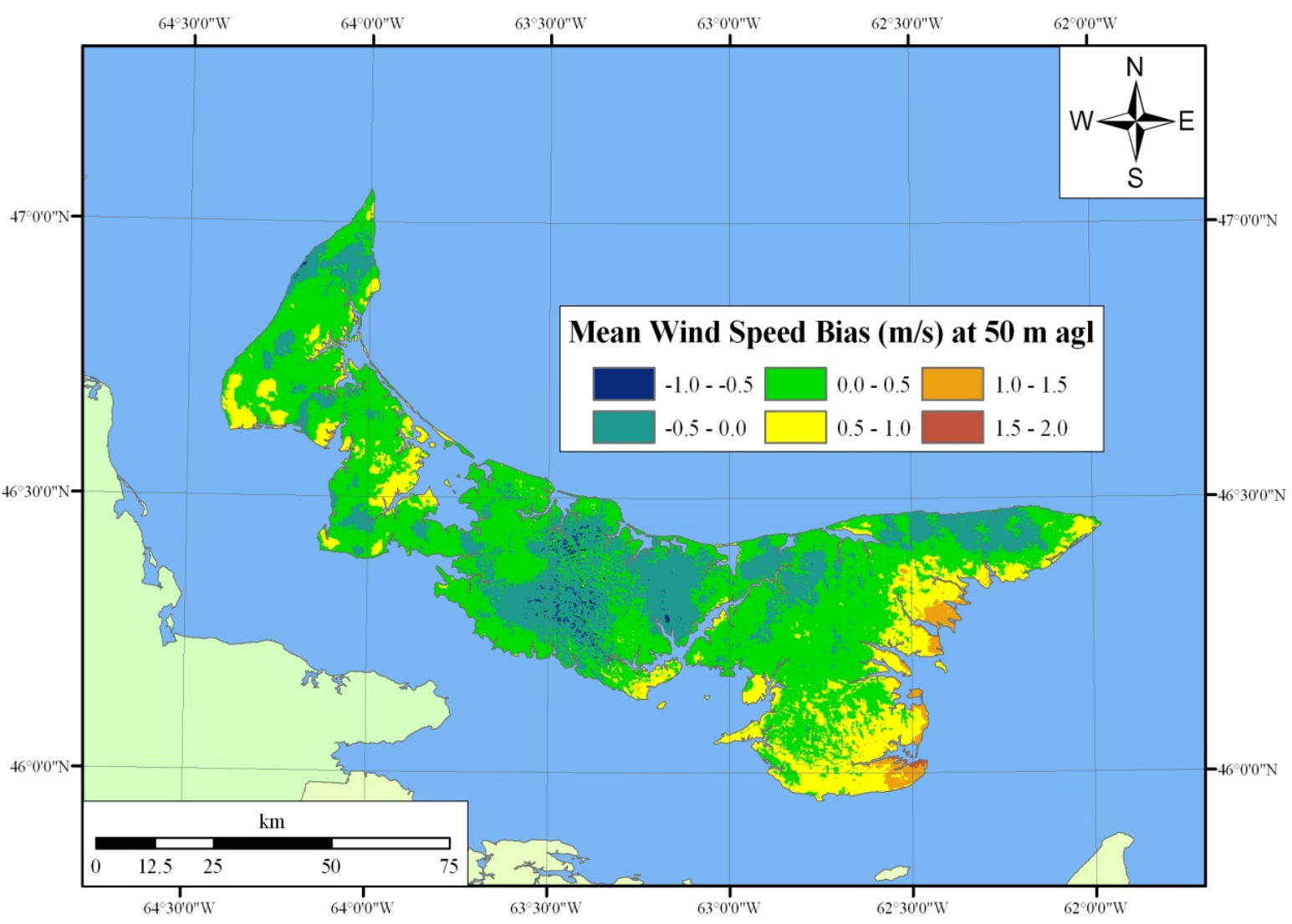


Figure 23. Probability density function of the microscale mean wind speed bias between CWEAHD-MsMicro and CWEA-WAsP scenarios at $50 \mathrm{~m}$ agl.

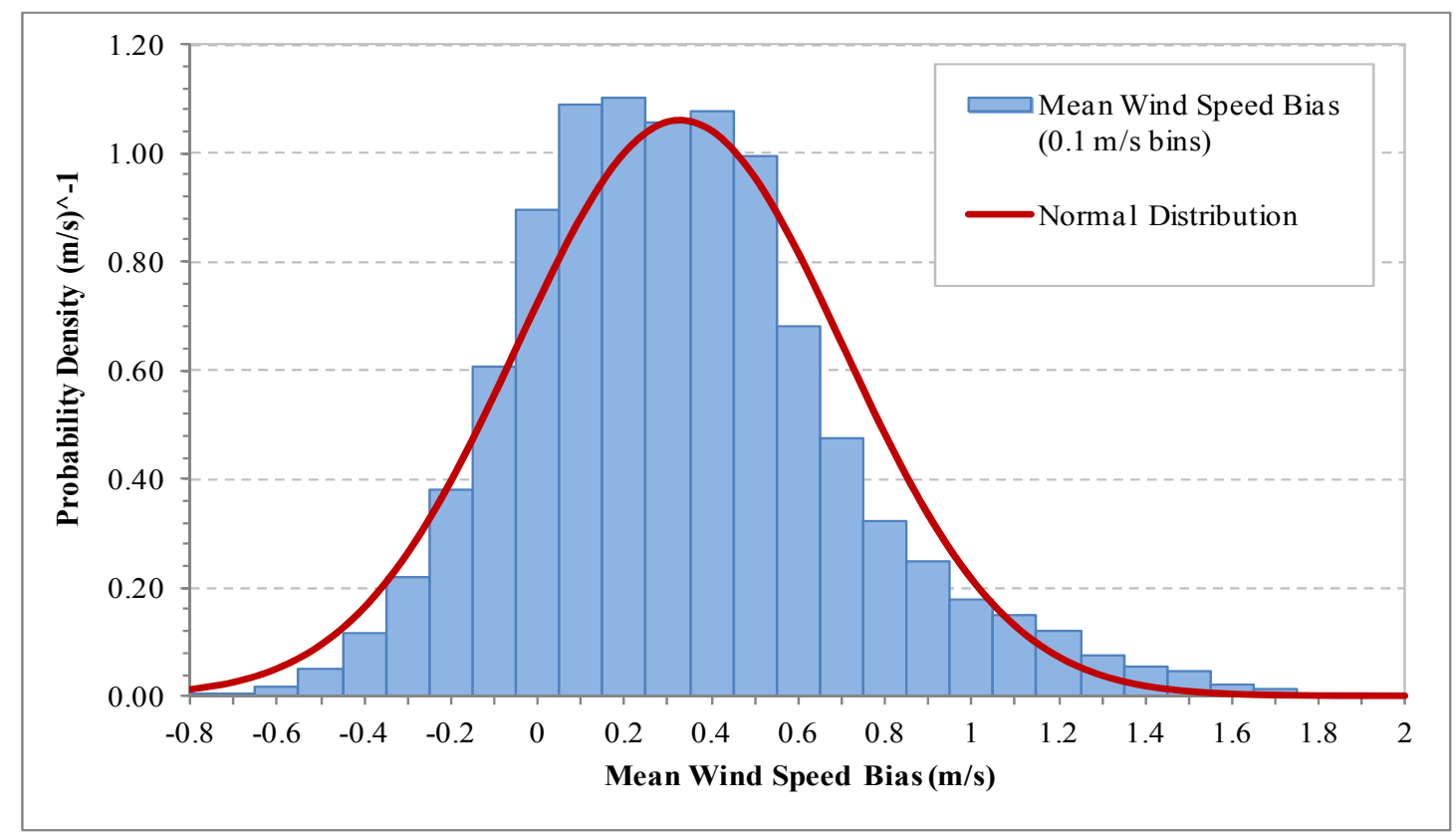

It is interesting to note that while the same input wind climate data is used in both the CWEA-MsMicro and the CWEA-WAsP microscale scenarios, the different roughness classifications lead to a generally lower roughness in the CWEA-WAsP scenario (see Figure 9). These results would suggest that the CWEA-WAsP scenario would generally obtain higher mean wind speeds than the CWEA-MsMicro scenario (as is the case between the CWEA and the CWEAHD scenarios). However, the opposite is observed. In fact, this may be caused by the additional transformations of the mesoscale wind climate data in the WAsP model (from an "observed wind climate" to a "regional wind climate" based on the mesoscale roughness descriptions) that appear to greatly affect the impacts of the microscale roughness height on the computed mean wind speed results.

Furthermore, the mesoscale roughness heights of the CWEA and the CWEA-WAsP scenarios in the central and western part of the province present similar values. At the microscale level, parts of the centre of the province also present similar roughness values in both the CWEA-WAsP and the CWEA-MsMicro/CWEAHD-MsMicro scenarios, and these values are very similar to the ones from the CWEA mesoscale dataset. As a result and since the roughness values are similar in these regions, the transformations from an "observed wind climate" to a "regional wind climate", as done in by the WAsP model, should not have large impacts on the final computed mean wind speeds in these regions and should be similar regardless of the modeling approach used. However, in the same region, the mean wind speed results obtained by the CWEA-MsMicro scenario are always higher than the results of the CWEA-WAsP scenario.

It is thus to conclude that not only does the transformations from an "observed wind climate" to a "regional wind climate", as done by the WAsP model, have an impact on the mean wind speed results, but the manner in which the model considers the roughness dataset also seems to have an effect on the computed mean wind speed results. It is also important to note, that while only smooth large scale differences were noted in the comparison between the mean wind speed results from the 
CWEA-MsMicro and the CWEAHD-MsMicro scenarios (see Figure 18), fine scale differences (at the level of the mesh) are notable in the comparisons of the microscale mean wind speed results from the CWEA-MsMicro/CWEAHD-MsMicro and CWEA-WAsP scenarios, Figures 20 and 22, respectively. In addition to the changes in the roughness classification, these small scale differences in mean wind speed results can also be attributed to the differences in the parameterization of the atmospheric boundary layer between the MsMicro and WAsP models, such as the internal boundary layer model which is included in the WAsP model but absent in the MsMicro model.

\subsection{Met Tower Comparisons of Mesoscale Results}

Figure 24 shows a comparison of observed wind speeds and computed mesoscale wind speeds at the met tower locations for both CWEA and CWEAHD scenarios. It is worth noting here that met towers are strongly influenced by their surrounding geophysical microscale features that are not captured by the coarse resolution of mesoscale models. As a result, such a comparison does not have strong quantitative meaning. However, as can be seen in Figure 24, both mesoscale CWEA and CWEAHD scenarios give similar results when compared to observations from the $50 \mathrm{~m}$ met towers. The modeling errors and subsequent statistical indicators for the comparisons are presented in Table 4. From Table 4, it is interesting to note that while the previous comparisons showed that the mesoscale CWEAHD mean wind speeds were generally slower than in the CWEA mesoscale scenario, the mean wind speeds computed at station locations for both approaches are approximately equal. However, it can be seen that the CWEAHD scenario has slightly lower model errors than the CWEA scenario, i.e., the RMSE and NRMSE errors for the CWEAHD scenario are 0.74 and $9.99 \%$ compared to 0.82 and $11.07 \%$ for the CWEA scenario, respectively.

Figure 24. Comparison of the CWEA and CWEAHD mesoscale results at $50 \mathrm{~m}$ agl.

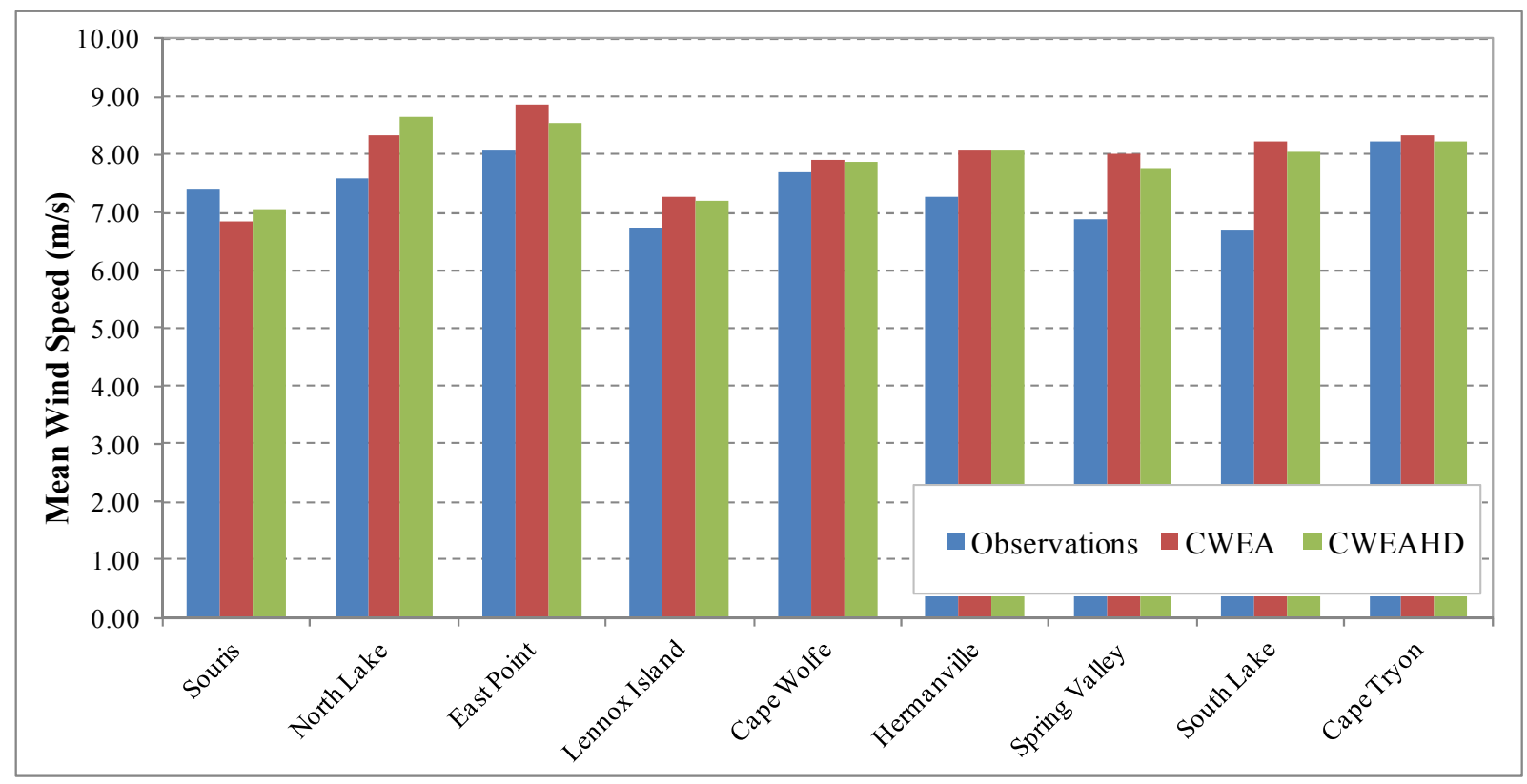


Table 4. Comparison of observed wind speeds and computed mesoscale wind speeds at the met tower locations.

\begin{tabular}{|c|c|c|c|c|c|c|c|c|}
\hline ID & Location Name & $\begin{array}{c}\text { Obs. Spd } \\
\text { at } 50 \mathrm{~m}(\mathrm{~m} / \mathrm{s})\end{array}$ & $\begin{array}{c}\text { CWEA Spd } \\
\text { at } 50 \mathrm{~m}(\mathrm{~m} / \mathrm{s})\end{array}$ & $\begin{array}{l}\text { CWEAHD Spd. } \\
\text { at } 50 \mathrm{~m}(\mathrm{~m} / \mathrm{s})\end{array}$ & $\begin{array}{c}\text { CWEA Diff. } \\
(\mathbf{m} / \mathbf{s})\end{array}$ & $\begin{array}{c}\text { CWEA Rel. } \\
\text { Diff. (\%) }\end{array}$ & $\begin{array}{l}\text { CWEAHD } \\
\text { Diff. (m/s) }\end{array}$ & $\begin{array}{c}\text { CWEAHD Rel. } \\
\text { Diff. (\%) }\end{array}$ \\
\hline PEIWA001 & Souris & 7.40 & 6.85 & 7.07 & -0.55 & -8.03 & -0.33 & -4.67 \\
\hline PEIWA002 & North Lake & 7.59 & 8.32 & 8.64 & 0.73 & 8.77 & 1.05 & 12.15 \\
\hline PEIWA003 & East Point & 8.09 & 8.87 & 8.53 & 0.78 & 8.79 & 0.44 & 5.16 \\
\hline PEIWA004 & Marshfield & - & - & - & - & - & - & - \\
\hline PEIWA005 & Lennox Island & 6.75 & 7.26 & 7.21 & 0.51 & 7.02 & 0.46 & 6.38 \\
\hline PEIWA006 & Cape Wolf & 7.68 & 7.92 & 7.86 & 0.24 & 3.03 & 0.18 & 2.29 \\
\hline PEIWA007 & Hermanville & 7.28 & 8.08 & 8.08 & 0.80 & 9.90 & 0.80 & 9.90 \\
\hline PEIWA008 & Spring Valley & 6.86 & 8.02 & 7.76 & 1.16 & 14.46 & 0.90 & 11.60 \\
\hline PEIWA009 & South Lake & 6.71 & 8.22 & 8.06 & 1.51 & 18.37 & 1.35 & 16.75 \\
\hline PEIWA010 & Cape Tryon & 8.24 & 8.34 & 8.24 & 0.10 & 1.20 & 0.00 & 0.00 \\
\hline $\begin{array}{l}\text { Averages }(\mathrm{m} / \mathrm{s}) \text {, } \\
\text { NMRE }(\%)\end{array}$ & $\operatorname{MRE}(\mathrm{m} / \mathrm{s})$ and & 7.40 & 7.99 & 7.94 & 0.59 & 7.93 & 0.54 & 7.28 \\
\hline $\operatorname{MAE}(\mathbf{m} / \mathbf{s}) \mathbf{a}$ & nd NMAE (\%) & & & & 0.71 & 9.58 & 0.54 & 7.26 \\
\hline $\operatorname{RMSE}(\mathrm{m} / \mathrm{s})$ a & nd NRMSE (\%) & & & & 0.82 & 11.07 & 0.74 & 9.99 \\
\hline $\operatorname{SDE}(\mathrm{m} / \mathrm{s}) \mathrm{a}$ & nd NSDE (\%) & & & & 0.61 & 8.19 & 0.54 & 7.26 \\
\hline
\end{tabular}




\subsection{Met Tower Comparisons of Microscale Results}

Figure 25 shows a comparison of observed wind speeds and computed microscale wind speeds at the met tower locations for the three microscale scenarios. From Figure 25, it can be seen that in general, both microscale CWEA-MsMicro and CWEAHD-MsMicro scenarios tend to overestimate the wind resource at the met tower locations, while the CWEA-WAsP scenario seems to equally underestimate and overestimate the wind resource. The modeling errors and subsequent statistical indicators for the comparison are presented in Table 5. From Table 5, it can be seen that when compared to observations from $50 \mathrm{~m}$ met towers, both microscale CWEA-MsMicro and CWEAHD-MsMicro scenarios give similar results as was the case in the mesoscale comparison. The scenario based upon higher resolution data, in this case the CWEAHD-MsMicro scenario, give slightly better results than the default resolution scenario, in this case the CWEA-MsMicro scenario, i.e., the RMSE and NRMSE errors for the CWEAHD-MsMicro scenario are $0.75 \mathrm{~m} / \mathrm{s}$ and $10.10 \%$ compared to $0.78 \mathrm{~m} / \mathrm{s}$ and $10.57 \%$ for the CWEA-MsMicro scenario, respectively. On the other hand, the CWEA-WAsP scenario has the lowest modeling errors with RMSE and NRMSE errors of $0.42 \mathrm{~m} / \mathrm{s}$ and $5.71 \%$, respectively. These results appear to suggest that, for the territory studied, the CWEA-WAsP scenario present notably better results than both microscale scenarios based on the MsMicro model.

Figure 25. Comparison of microscale results at $50 \mathrm{~m}$ agl.

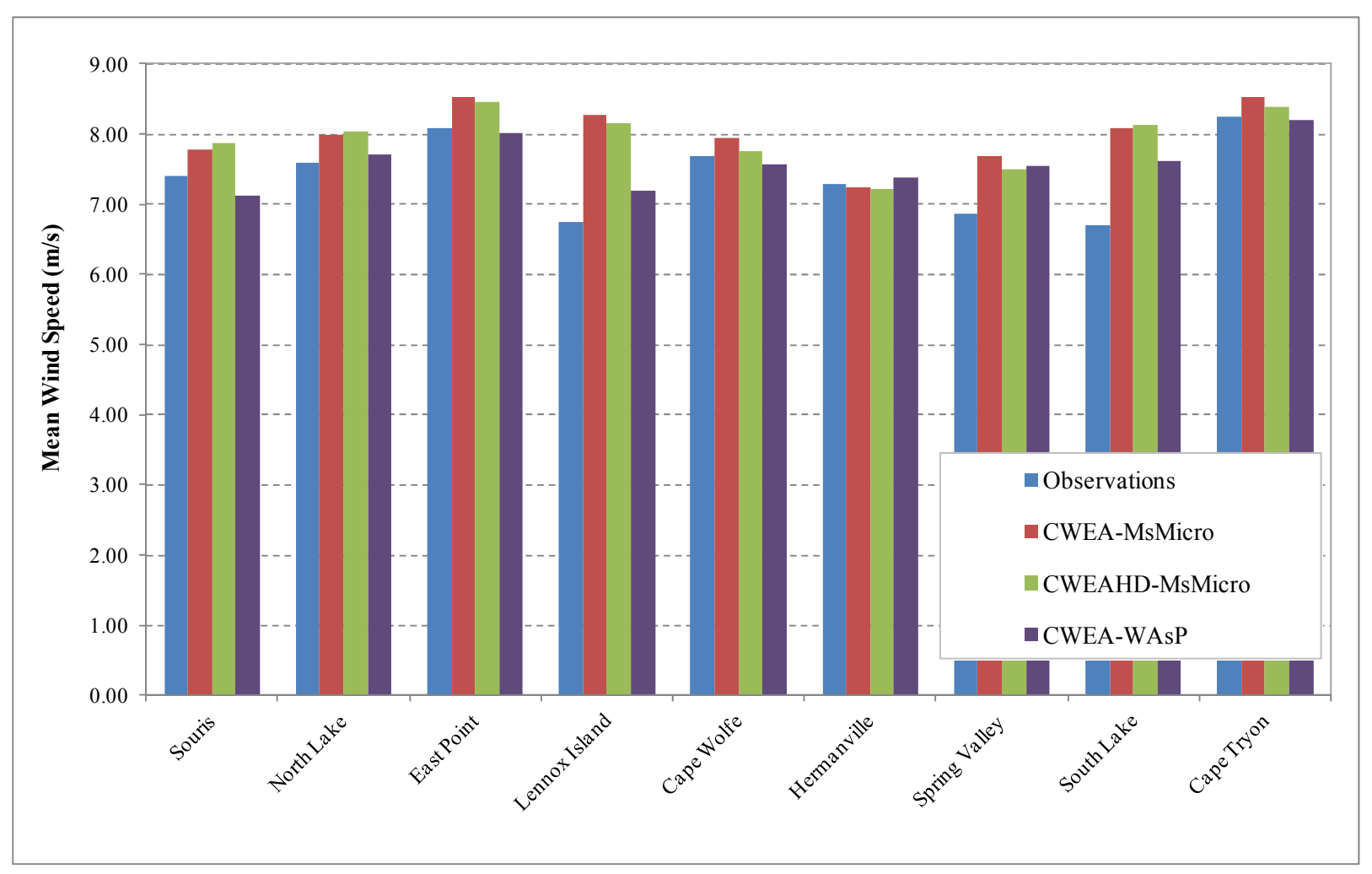


Table 5. Comparison of observed wind speeds and computed microscale wind speeds at the met tower locations.

\begin{tabular}{|c|c|c|c|c|c|c|c|c|c|c|c|}
\hline ID & $\begin{array}{l}\text { Location } \\
\text { Name }\end{array}$ & $\begin{array}{c}\text { Obs. } \\
\text { Spd at } \\
\mathbf{5 0 ~} \mathbf{~ m} \\
(\mathbf{m} / \mathbf{s})\end{array}$ & 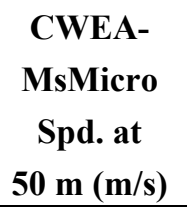 & $\begin{array}{l}\text { CWEAHD- } \\
\text { MsMicro } \\
\text { Spd. at } \\
50 \mathrm{~m} \mathrm{(m/s)}\end{array}$ & 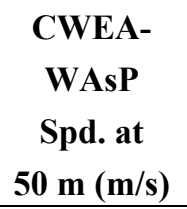 & $\begin{array}{l}\text { CWEA- } \\
\text { MsMicro } \\
\text { Diff. (m/s) }\end{array}$ & $\begin{array}{c}\text { CWEA- } \\
\text { MsMicro Rel. } \\
\text { Diff. (\%) }\end{array}$ & $\begin{array}{l}\text { CWEAHD- } \\
\text { MsMicro } \\
\text { Diff. (m/s) }\end{array}$ & $\begin{array}{c}\text { CWEAHD- } \\
\text { MsMicro Rel. } \\
\text { Diff. (\%) }\end{array}$ & $\begin{array}{c}\text { CWEA- } \\
\text { WAsP Diff. } \\
(\mathbf{m} / \mathbf{s})\end{array}$ & $\begin{array}{c}\text { CWEA- } \\
\text { WAsP Rel. } \\
\text { Diff. (\%) }\end{array}$ \\
\hline PEIWA001 & Souris & 7.40 & 7.79 & 7.86 & 7.12 & 0.39 & 5.00 & 0.46 & 5.88 & -0.28 & -3.89 \\
\hline PEIWA002 & North Lake & 7.59 & 7.98 & 8.03 & 7.72 & 0.39 & 4.89 & 0.44 & 5.51 & 0.13 & 1.65 \\
\hline PEIWA003 & East Point & 8.09 & 8.52 & 8.46 & 8.01 & 0.43 & 5.08 & 0.37 & 4.39 & -0.08 & -1.00 \\
\hline PEIWA004 & Marshfield & - & - & - & - & - & - & - & - & - & - \\
\hline PEIWA005 & Lennox Island & 6.75 & 8.27 & 8.16 & 7.20 & 1.52 & 18.40 & 1.41 & 17.26 & 0.45 & 6.27 \\
\hline PEIWA006 & Cape Wolf & 7.68 & 7.94 & 7.75 & 7.57 & 0.26 & 3.28 & 0.07 & 0.88 & -0.11 & -1.49 \\
\hline PEIWA007 & Hermanville & 7.28 & 7.24 & 7.22 & 7.39 & -0.04 & -0.54 & -0.06 & -0.80 & 0.11 & 1.50 \\
\hline PEIWA008 & Spring Valley & 6.86 & 7.68 & 7.51 & 7.53 & 0.82 & 10.63 & 0.65 & 8.65 & 0.67 & 8.95 \\
\hline PEIWA009 & South Lake & 6.71 & 8.08 & 8.14 & 7.62 & 1.37 & 16.97 & 1.43 & 17.56 & 0.91 & 11.92 \\
\hline PEIWA010 & Cape Tryon & 8.24 & 8.53 & 8.39 & 8.21 & 0.29 & 3.37 & 0.15 & 1.78 & -0.03 & -0.36 \\
\hline \multicolumn{2}{|c|}{$\begin{array}{l}\text { Averages }(\mathrm{m} / \mathrm{s}), \text { MRE }(\mathrm{m} / \mathrm{s}) \\
\text { and NMRE }(\%)\end{array}$} & 7.40 & 8.00 & 7.95 & 7.60 & 0.60 & 8.15 & 0.55 & 7.39 & 0.20 & 2.66 \\
\hline \multicolumn{2}{|c|}{ MAE (m/s) and NMAE (\%) } & & & & & 0.61 & 8.27 & 0.56 & 7.56 & 0.31 & 4.16 \\
\hline \multicolumn{2}{|c|}{ RMSE $(\mathrm{m} / \mathrm{s})$ and NRMSE (\%) } & & & & & 0.78 & 10.57 & 0.75 & 10.10 & 0.42 & 5.71 \\
\hline \multicolumn{2}{|c|}{ SDE $(\mathrm{m} / \mathrm{s})$ and NSDE $(\%)$} & & & & & 0.53 & 7.13 & 0.54 & 7.30 & 0.40 & 5.36 \\
\hline
\end{tabular}




\section{Discussion and Conclusions}

In this work, mean wind speeds from several wind flow modeling methodologies were examined and compared to observational mean wind speed measurements from several $50 \mathrm{~m}$ met towers distributed across the study area. At the mesoscale level, with a $5 \mathrm{~km}$ resolution, two scenarios were examined based on the MC2 model: the CWEA scenario and the CWEAHD scenario where, in the latter, a high resolution up-to-date land cover dataset is used. At the microscale level, two microscale models are compared: MsMicro and WAsP. To this end, mean wind speed values from a CWEA-WAsP modeling approach were compared to two other scenarios based on a CWEA-MsMicro modeling approach, i.e., the CWEA-MsMicro and the CWEAHD-MsMicro scenarios. Results showed that with a modeling approach based on the MC2 and MsMicro models, higher resolution land cover and topography datasets, used to generate model surface input data, help reduce modeling errors for both the mesoscale and microscale models, albeit only marginally. At the microscale level, when computational results were compared to observational data from met towers, it was shown that, for the territory studied, the CWEA-WAsP modeling approach gave substantially better results than both CWEA-MsMicro and CWEAHD-MsMicro modeling approaches. Results showed that the predicted mean wind speeds by the CWEA-WAsP scenario are generally lower than those of the CWEA-MsMicro and the CWEAHD-MsMicro scenarios and are closer to the observational mean wind speeds measurements. It was found that, in comparison with the results from the other scenarios, several aspects of the CWEA-WAsP modeling approach contributed to lower final mean wind speeds results; of them, the most important ones are the transformations of the mesoscale wind climate data from an "observed wind climate" to a "regional wind climate", as done by the WAsP model, and the development of dedicated microscale and mesoscale roughness maps for the CWEA-WAsP scenario. For its part, the difference in the parameterization of the atmospheric boundary layer between the MsMicro and WAsP models, such as the internal boundary layer model which is included in the WAsP model but absent in the MsMicro model, may also play a role in the results.

Finally, the results of this study seem to suggest that for the territory studied, the WAsP model appears to be better adapted in approximating the atmospheric boundary layer than the MsMicro model. Future work includes, on one hand, a more detailed evaluation of the impacts of the transformations of the mesoscale wind climate data from an "observed wind climate" to a "regional wind climate" as done by the WAsP model; while on the other hand, in order to validate the methodology, an application of the modeling approaches to other territories is also planned, notably where longer term observational datasets are available.

\section{Acknowledgements}

The PEI Wind Atlas Project was funded under a research contract with the PEI Energy Corporation, while the research work of the K.C. Irving Chair in Sustainable Development is funded by the Natural Sciences and Engineering Research Council (NSERC) of Canada and the New Brunswick Innovation Foundation (NBIF). 


\section{References}

1. European Wind Energy Association (EWEA). Wind Energy-The Facts: An Analysis of Wind Energy in the EU-25; Report for European Commission's Directorate General for Transport and Energy (DG TREN) and European Commission: London, UK, 2005.

2. Taylor, P.A.; Teunissen, H.W. The Askervein Hill project: Overview and background data. Bound. Layer Meteorol. 1987, 39, 15-39.

3. Walmsley, J.L.; Morris, R.J. Wind Energy Resource Map of Canada; Report ARD-92-003-E; Atmospheric Environment Service, Environment Canada (EC): Ottawa, Canada, 1992.

4. Canadian Wind Energy Atlas at $5 \mathrm{~km}$. EOLE Wind Energy Project, 2005. Available online: http://www.windatlas.ca (accessed on 9 January 2012).

5. Yu, W.; Benoit, R.; Girard, C.; Glazer, A.; Lemarquis, D.; Salmon, J.R.; Pinard, J.P. Wind Energy Simulation Toolkit (WEST): A wind mapping system for use by wind energy industry. Wind Eng. 2006, 30, 15-33.

6. Landberg, L.; Myllerup, L.; Rathmann, O.; Petersen, E.L.; Jørgensen, B.H.; Badger, J.; Mortensen, N.G. Wind resource estimation-An overview. Wind Energy 2003, 6, 261-271.

7. Mengelkamp, H.-T.; Kapitza, H.; Pflüger, U. Statistical-dynamical downscaling of wind climatologies. J. Wind Eng. Ind. Aerodyn. 1997, 67-68, 449-457.

8. Benoit, R.; Desgagné, M.; Pellerin, P.; Pellerin, S.; Chartier, Y.; Desjardins, S. The Canadian MC2: A semi-lagrangian, semi-implicit wideband atmospheric model suited for finescale process studies and simulation. Mon. Weather Rev. 1997, 125, 2382-2415.

9. Walmsley, J.L.; Taylor, P.A.; Keith, T. A simple model of a neutrally stratified boundary-layer flow over complex terrain with surface roughness modulations (MS3DJH/3R). Bound. Layer Meteorol. 1986, 36, 157-186.

10. WAsP-Wind Atlas Analysis and Application Program; Risø National Laboratory: Roskilde, Denmark, 2005.

11. Gasset, N.; Gagnon, Y.; Poitras, G.J. Prince Edward Island Wind Atlas; Université de Moncton, PEI Energy Corporation, 2005. Available online: http://www.peiwindatlas.ca (accessed on 14 January 2012).

12. Recherche en Prévision Numérique of Environment Canada and the Canadian Hydraulics Center of the National Research Council Canada. Anemoscope-Wind Energy Simulation Toolkit; 2005. Available online: http://www.anemoscope.ca/Intro_en.html (accessed on 12 January 2012).

13. Wind Energy Simulation Toolkit, Open Source Edition (WEST OSE), 2012. Available online: $\mathrm{http}: / /$ sourceforge.net/projects/westose/ (accessed on 10 January 2012).

14. Mallet, M.; Gagnon, Y.; Poitras, G.J.; Gasset, N. New Brunswick Wind Atlas; Report of the K.C. Irving Chair in Sustainable Development, Université de Moncton, 2007. Available online: http://www.nbwindatlas.ca (accessed on 12 January 2012).

15. Thibault, R.; Gagnon, Y.; Colville, D.; Bird, S. Nova Scotia Wind Atlas; Report of the K.C. Irving Chair in Sustainable Development, Université de Moncton, 2007. Available online: http://www.nswindatlas.ca (accessed on 14 January 2012).

16. PEI Energy Accord Backgrounder; Government of Prince Edward Island: Charlottetown, Canada, 2010. 
17. Island Wind Energy, Securing our Future: The 10 Point Plan; Government of Prince Edward Island: Charlottetown, Canada, 2008.

18. Petersen, E.L.; Mortensen, N.G.; Landberg, L.; Højstrup, J.; Frank, H.P. Wind power meteorology. Part II: Sitting and models. Wind Energy 1998, 1, 55-72.

19. Ayotte, K. Computational modelling for wind energy assessment. J. Wind Eng. Ind. Aerodyn. 2008, 96, 1571-1590.

20. Holton, J.R. An Introduction to Dynamic Meteorology; Elsevier Academic Press: London, UK, 2004.

21. Stull, R.B. An Introduction to Boundary Layer Meteorology; Kluwer Academic Publishers: Dordrecht, The Netherlands, 1988.

22. Frank, H.P.; Rathmann, O.; Mortensen, N.G.; Landberg, L. The Numerical Wind Atlas-The KAMM/WAsP Method; Report Risø-R-1252(EN); Risø National Laboratory: Roskilde, Denmark, 2001. Available online: http://www.risoe.dtu.dk/knowledge_base/publications/reports/ris-r-1252.aspx (accessed on 4 May 2012)

23. TrueWinds Solution. Wind Energy Resource Maps of the Republic of Ireland; Report for ESBI International: Albany, NY, USA, 2003.

24. Girard, C.; Benoit, R.; Desgagné, M. Finescale Topography and the MC2 Dynamics Kernel. Mon. Weather Rev. 2005, 133, 1463.

25. Russo, J.M.; Zack, J.W. Downscaling GCM Output with a Mesoscale Model. J. Environ. Manag. 1997, 49, 19-29.

26. Gasset, N.; Poitras, G.J.; Gagnon, Y.; Brothers, C. Study of atmospheric boundary layer flows over a coastal cliff. Wind Eng. 2005, 29, 3-24.

27. Jackson, P.S.; Hunt, J.C.R. Turbulent wind flow over a low hill. Q. J. R. Meteorol. Soc. 1975, 101, 929-955.

28. Finardi, S.; Brusasca, G.; Morselli, M.G.; Trombetti, F.; Tampieri, F. Boundary-layer flow over analytical two-dimensional hills: A systematic comparison of different models with wind tunnel data. Bound. Layer Meteorol. 1993, 63, 259-291.

29. Troen, I.; Petersen, E.L. European Wind Atlas; Risø National Laboratory: Roskilde, Denmark, 1989.

30. Description of the MesoMap System; Internal Report; AWS Truepower, LLC: Albany, NY, USA, 2012.

31. Kalnay, E.; Kanamitsu, M.; Kistler, R.; Collins, W.; Deaven, D.; Gandin, L.; Iredell, M.; Saha, S.; White, G.; Woollen, J.; et al. The NCEP'NCAR 40-Year Reanalysis Project. Bull. Amer. Meteor. Sco. 1996, 77, 437-471.

32. US Geological Survey. Available online: http://www.usgs.gov (accessed on 1 September 2012).

33. Geobase. Canadian Digital Elevation Data (CDED). Available online: http://www.geobase.ca (accessed on 9 January 2012).

34. Prince Edward Island Energy Corporation, Department of Environment, Energy and Forestry of PEI, Government of Prince Edward Island. Available online: http://www.gov.pe.ca/eef/ (accessed on 10 January 2012). 
35. Wieringa, J. Representative roughness parameters for homogeneous terrain. Bound. Layer Meteorol. 1993, 63, 323-363.

(C) 2012 by the authors; licensee MDPI, Basel, Switzerland. This article is an open access article distributed under the terms and conditions of the Creative Commons Attribution license (http://creativecommons.org/licenses/by/3.0/). 